\title{
MORPHOLOGICAL AND SYNTACTIC TRANSFER IN CHILD L2 ACQUISITION OF THE ENGLISH DATIVE ALTERNATION
}

\author{
Melinda Whong-Barr \\ University of Durham \\ Bonnie D. Schwartz \\ University of Hawai' $i$
}

\begin{abstract}
This experimental study compares the acquisition of the English toand for-dative alternation by L1 English, L1 Japanese, and L1 Korean children. It is well known that there are restrictions on the verbs that can enter into the dative alternation-for example, you can show the results to someone and show someone the results; and you can demonstrate the results to someone but you cannot *demonstrate
\end{abstract}

\begin{abstract}
The impetus for this paper was the Master's dissertation of Whong-Barr (1999), for which the data collection was funded by the University of Durham sponsored ACCESS (Adult and Child Crosslinguistic English Second Syntax) project, codirected by Martha Young-Scholten and the second author. We are grateful for that support. The second author also acknowledges with gratitude the support of a 1999 Research Leave Award from the Arts and Humanities Research Board. We extend our sincere appreciation to the children who participated in this study as well as their parents, in particular those associated with the Washington Japanese Saturday School. We are indebted to Joe Emonds (again) for innumerable discussions, to Donna Lardiere, Silvina Montrul, Cathy O'Connor, Rex Sprouse, and Lydia White for many helpful comments on form and substance, and to three anonymous SSLA reviewers for instructive criticisms. Earlier versions of this paper were presented at the University of Durham, the Tokyo Conference on Psycholinguistics, the Linguistics Association of Great Britain, the University of Ottawa, the Boston University Conference on Language Development, the University of Hawai i, and the University of Southern California. We thank those audiences for feedback and are especially appreciative of the support from Mr. Sin Hung Ng of Happy Travel for making the trip to Tokyo possible. Thanks also to Mamiko Akita, Seiki Ayano, Alison Bennett, Claire Fawcett, Sarah Hepworth, Rachel Hogarth, Up Yong Hong, Claire Jones, Hye-Kyung Kang, Chul-kyu Kim, Jeong-Young Kim, Mika Kizu, Young-Geon Lee, Kyoko Oga, William O'Grady, Hiromi Ozaki, Susan Pintzuk, Mayumi Saiki, Roumyana Slabakova, Gihoon Song, David Stringer, Satoshi Tomioka, John Whitman, and James Yoon for help on various aspects leading up to this paper, including their native judgments.

Address correspondence to: Melinda Whong-Barr, Department of Linguistics and English Language, University of Durham, Elvet Riverside II, New Elvet, Durham DH1 3JT, United Kingdom; e-mail: m.k.whong-barr@durham.ac.uk.
\end{abstract}


someone the results. L1 children sometimes overextend the doubleobject variant to verbs that disallow it. One question we investigate is whether L2 children, like L1 children, overextend the double-object variant. A second question we probe is whether $L 2$ children, like $L 2$ adults, transfer properties of the L1 grammar. Japanese disallows all double-accusative constructions. Korean disallows them with analogues of to-dative verbs; but with analogues of for-dative verbs, Korean productively allows them-more broadly, in fact, than English-if the benefactive verbal morpheme cwu- is added. Results from an oral grammaticality judgment task show (a) that all groups allow illicit to-dative double-object forms and (b) that the Japanese-but not the Koreans-allow illicit for-dative double-object forms. This bifurcation, we argue, stems from the fact that Korean (but not Japanese) has an overt morphological licensor for double objects. We thus find evidence of both (a) overgeneralization, like in $L 1$ acquisition, and (b) $L 1$ influence, like in adult $L 2$ acquisition, in this case from the (syntactic) argument-changing properties of overt morphology.

In the acquisition of nonnative language (L2), it is widely assumed that the younger the L2 acquirer, the more likely it is that the ultimate level of attainment will be nativelike (e.g., Johnson \& Newport, 1989). Child L2 acquirers are assumed not to face the same obstacles as their adult counterparts, at least in the relevant respects spelled out by the Fundamental Difference Hypothesis (Bley-Vroman, 1990). L2 children in this respect are like native children in that sustained target language exposure over a few years leads to general "success." This is not to say that child L2 development necessarily replicates native language (L1) development. The most noticeable difference between L1 acquisition and child L2 acquisition is the fact that L2 children come to the language acquisition task with (more or less complete) knowledge of a specific grammar. In this respect, L2 children are like L2 adults.

The tension between these two points of comparison in child L2 acquisition forms the foundation for this study. Our interest is in how the development of an L2 in children might be like L1 development and how it might be like adult L2 development. Will the same types of developmental errors that are found in L1 acquisition be found in child L2 acquisition? Will the same type of L1 influence that is found in adult L2 acquisition be found in child L2 acquisition? These are the two main questions this paper attempts to address.

Our study concerns child L2 acquisition of the English dative alternationthat is, the two syntactic environments in which verbs such as give can occur: One can give a painting to the museum or give the museum a painting. However, it is well known that the class of verbs that enters into the dative alternation is restricted. For example, unlike give, donate does not allow the double-object 
variant: One can donate a painting to the museum, but one cannot *donate the museum a painting. How do English speakers come to know which verbs allow the dative alternation? An early suggestion (Baker, 1979) was that acquirers are conservative and rely only on the input, learning the argument-taking properties of verbs one by one. However, as will be discussed, L1 children have been found to be productive rather than conservative, allowing doubleobject forms that could not have been part of their input. Yet in time native English speakers know which verbs take part in the dative alternation and which do not. In short, the dative alternation, like other argument-structure alternations, is widely recognized as an exemplar of the poverty of the stimulus problem: From a limited set of data in the input, the language acquirer must somehow determine, in the absence of negative evidence, which verbs allow the alternating syntactic forms and which ones do not. The L1 acquisition of the dative alternation must somehow rely on internal mechanisms, enabling children eventually to deduce general rules and restrictions from limited input.

This same learnability problem holds for L2 acquisition as well (Juffs, 1996), most obviously for children acquiring their L2 naturalistically. Child L2 acquirers of English who come to know which verbs do and which verbs do not allow the dative alternation must also have relied on internal mechanisms to do so. However, there may be another potential internal source for the knowledge of argument-structure alternation: their L1 grammar. Drawing on the premises of the Full Transfer-Full Access model (FT-FA; Schwartz \& Sprouse, 1994, 1996), our study investigates the issue of transfer in the child L2 acquisition of the English dative alternation. FT-FA hypothesizes that the initial state of L2 acquisition is the grammar of the L1 (excluding the phonetic matrices of lexical-morphological items) and that L2 development occurs through UGconstrained restructuring as target language input conflicts with what the current state of the Interlanguage grammar can generate. If in regard to particular (lexico-syntactic) properties-here, the dative alternation-L2 acquirers' L1s are distinct, then with respect to these particular properties FT-FA posits that their L2 initial states will be different and hence predicts that their L2 developmental paths will also necessarily differ (even if they should happen ultimately to converge with each other or the target language grammar). This experimental study thus compares the L2 acquisition of English by children whose L1s differ precisely in terms of the dative alternation: Korean, which allows the double-accusative construction in some circumstances (in fact, even more broadly than English does), and Japanese, which systematically disallows it.

On a general level, our hypothesis is twofold: Child L2 acquisition of the English double-object construction will exhibit (a) developmental differences where the L1s differ, and, at the same time, (b) overgeneralization, like in L1 acquisition. Expecting differences based on the L1s, we also propose more specific hypotheses concerning the level at which transfer occurs-namely, syntax, morphology, or both. The results suggest, in line with Montrul (1997), 
that overt (derivational) morphology does figure in interesting ways into the transfer equation.

The paper is organized as follows. The first section lays out the theoretical background concerning the dative alternation for each of the three languages, including the issue of equivalence between languages for the relevant constructions. Next we examine previous L1 and L2 acquisition research involving the English dative alternation that bears directly on our study. We then present our experiment itself, an oral grammaticality judgment task that tested three groups of children (L1 English, L1 Japanese, and L1 Korean) on the two variants of the English dative alternation. We close with a discussion of how the effects of transferring argument-changing morphology depend on the relevant properties of the L1 and the target language-and how intriguingly different these effects can be.

\section{THEORETICAL BACKGROUND}

\section{English}

Baker (1979) is most often credited with recognizing the learnability problem embodied by the dative alternation. The puzzle is as follows: Why is it that the prepositional dative (hereafter PD) and the double-object dative (hereafter DOD) in (1) and (3) are grammatical, whereas in (2) and (4) only the PD forms are grammatical?

(1) a. Nikki showed the picture to Lauren.

b. Nikki showed Lauren the picture.

(2) a. Nikki described the picture to Lauren. b. *Nikki described Lauren the picture.

(3) a. Sydney found the money for Meleeya. b. Sydney found Meleeya the money.

(4) a. Sydney collected the money for Meleeya. b. *Sydney collected Meleeya the money. (prepositional to-dative) (double-object to-dative)

(prepositional to-dative) ( ${ }^{*}$ double-object to-dative)

(prepositional for-dative) (double-object for-dative)

(prepositional for-dative) ( ${ }^{*}$ double-object for-dative)

It is generally accepted that there is some restriction disallowing some verbs from being realized in both the PD and the DOD forms. The agreement among syntactic as well as lexical-semantic analyses is that some sort of "possession constraint" is at work (Aoun \& Li, 1989; Goldsmith, 1980; Grimshaw, 1989; Jackendoff, 1990; Larson, 1988; Pinker, 1989, among others). For an oblique object in a PD form to be alternately realized as a direct object in a DOD form, the first object of the DOD variant (also known as the "shifted object") must be a potential possessor. Thus, for to-datives like (1b) and (2b), the first object must be a potential possessor in addition to being the Goal, and for for-datives like (3b) and (4b), this object must be the potential possessor in addition to the Beneficiary.

Consider how the possession constraint is derived in a lexical-semantic ac- 
count like that of Pinker (1989). The semantic structure or "thematic core" of a verb is formed by a limited set of primitive semantic functions, including ACT, CAUSE, HAVE, and GO, together with arguments. Taking as illustration the alternation in (1) with to-dative verbs, the PD form realizes a thematic core in which "X causes $\mathrm{Y}$ to go to Z." The semantic arguments X, Y, and Z are mapped onto their syntactic arguments via so-called universal linking rules: $X$ onto subject, $\mathrm{Y}$ onto direct object, and $\mathrm{Z}$ onto the oblique object of the preposition to. The DOD form, by contrast, has the thematic core " $\mathrm{X}$ causes $\mathrm{Z}$ to have Y"; in this case, $\mathrm{Z}$ is linked to first object position. It is the existence of the semantic primitive HAVE in this semantic structure that signals possession in the DOD: Z, the Goal, also possesses Y, the Theme, at least potentially. ${ }^{2}$

Pinker (1989) characterized the relationship between these two thematic cores in the form of a rule, a so-called Broad Range Rule, which takes as input the thematic core of the PD and converts it to the thematic core of the DOD. This Broad Range Rule (the possession constraint) is seen as a necessary but not sufficient condition on the dative alternation. Whether a particular verb actually allows the two alternate syntactic structures is said to be determined by two further constraints: first, Narrow Range Rules, which apply to narrower verb classes that already satisfy the Broad Range Rule and are based on "linguistically relevant" semantic components (e.g., Levin, 1993); and second, a morphophonological constraint that seems to rule out most Latinate verbs from occurring in the DOD form (Green, 1974). ${ }^{3}$ Thus, for example, in (1) and (2), show, from the class of "illocutionary verbs of communication" (Pinker, p. 112), allows both DOD and PD forms, whereas describe, a verb of the same class but of Latinate origin, is licit only in the PD form.

In the Pinker (1989) framework, in sum, acquirers of the English dative alternation must come to know three things: the general Broad Range Dative Rule relating the semantic structures underlying the PD and DOD forms, the Narrow Range Dative Rules that further narrow by class which verbs alternate, and the Latinate constraint. Not surprisingly, it is not the case that all languages allow argument-structure alternations analogous to the English dative alternation, nor in languages that do is the dative alternation subject to the same constraints found in English. Japanese and Korean are two such languages that differ from English-and from each other-in terms of whether there is an alternation and how it works.

\section{Japanese and Korean}

Japanese never allows two accusative-marked objects to co-occur in the same clause. This is due to the well-known Double-o Constraint (Harada, 1973; Poser, 1981). ${ }^{4}$

(5)

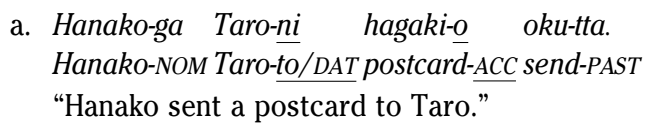


b. *Hanako-ga Taro-o hagaki-o oku-tta. Hanako-NOM Taro-ACC postcard-ACC send-PAST

(6) a. Hanako-ga Taro(-no tame)-ni e-o kai-ta. Hanako-NOM Taro (-GEN sake)-for/DAT picture-ACC draw-PAST "Hanako drew a picture for Taro."

b. *Hanako-ga Taro-o e-o kai-ta. Hanako-NOM Taro-ACC picture-ACC draw-PAST

The double accusatives in (5b) and (6b) are uncontroversially ruled out in Japanese. However, it is a matter of debate as to whether the grammatical structures underlying (5a) and (6a) are the equivalent of the PD form or the DOD form in English. ${ }^{5}$ At issue is the status of the -ni particle (Kuroda, 1965). As argued by Sadakane and Koizumi (1995), "Japanese has several homophonous particles $n i$, including the postposition $n i$ and the dative case marker $n i$, as well as a couple of other types of $n i$ (p. 6). If $-n i$ is a postposition, then (5a) and (6a) would be considered equivalent to the English PD; if $-n i$ is a dative case marker, then (5a) and (6a) may be more equivalent to the English DOD structure. ${ }^{6}$

We maintain, however, that (5a) and (6a) cannot be likened to the DOD construction in English even if $-n i$ is a dative case marker because the shifted object in the English equivalent is certainly not a dative-marked object. We follow proposals such as Larson (1988) and Johnson (1991), which argue that the shifted object in English has structural objective case. Thus, even if -ni is a dative case marker, the NP to which it is attached cannot be equated with the shifted object in the English DOD variant. The exact status of -ni is in fact irrelevant; of importance is the claim that Japanese exhibits no instance of double direct-object constructions and hence that there is no alternation in Japanese analogous to the English dative alternation.

Korean is like Japanese with regard to the to-dative construction; most Korean to-dative verbs, as in (7), do not allow a double-accusative form. ${ }^{7}$

(7) a. Mia-ka Yong-eykey kulim-yepse-lul ponay-ss-ta. Mia-NOM Yong-to/DAT picture-card-ACC send-PAST-DECL "Mia sent a postcard to Yong."

b. *Mia-ka Yong-ul kulim-yepse-lul ponay-ss-ta. Mia-NOM Yong-ACC picture-card- $\overline{A C C}$ send-PAST-DECL

As with Japanese -ni, the -eykey particle is also subject to debate as to whether it is a postposition or a dative case marker (Hong, 1991; O'Grady, 1991). Again, as previously argued for -ni, the exact nature of this particle is irrelevant, as the -eykey-marked NP cannot be equated with the shifted object of English; there is thus no double direct-object form, hence no alternation, for Korean to-dative verbs.

Korean benefactive for-datives, by contrast, do alternately allow the double-accusative construction, as in (8b); that is, the Goal/Beneficiary object Yong in (8) can alternately be marked with accusative case (Choe, 1986; O'Grady, 1991; Song, 1993). 
(8) a. Mia-ka Yong-eykey kulim-ul kuly-e cwu-ess-ta. Mia-NOM Yong-for/DAT picture-ACC draw-L BEN-PAST-DECL

"Mia drew a picture for Yong."

b. Mia-ka Yong-ul kulim-ul kuly-e cwu-ess-ta.

Mia-NOM Yong-ACC picture-ACC draw-L $\underline{B E N-P A S T-D E C L}$

"Mia drew Yong a picture."

With benefactive for-datives, Korean allows double accusatives with a wider range of verbs than English does. ${ }^{8}$ Notice that the sentences in (8) include the verbal morpheme $c w u$ - The ability to add $c w u$ - to another verb to form the benefactive verbal construction is extremely productive (Choe; Hong, 1991). Furthermore, leaving out the $c w u$ - morpheme, as in (9), leads to ungrammaticality (Hong).

(9) *Mia-ka Yong-eykey/-ul kulim-ul kuly-ess-ta.

Mia-NOM Yong-for/DAT/-ACC picture-ACC draw-PAST-DECL

Combining $\mathrm{cwu}$ - with other verbs results in the Goal NP getting an additional Beneficiary reading (Hong; J. Yoon, personal communication, 6 June 2000). That is, the presence of $c w u$ - forces a benefactive interpretation, as shown by the incongruous (10).

(10) \#Yong-i amwulen heythayk-ul patci anhnun sanghwangeyseto, Yong-NOM any benefit-ACC receive NEG situation Mia-ka Yong-eykey/-ul kulim-yepse-lul ponay cwu-ess-ta. Mia-NOM Yong-for/DAT/-ACC picture-card-ACC send BEN-PAST-DECL

"Even though it was not to Yong's benefit, Mia sent a postcard to Yong."

We suggest that the benefactive double accusative in Korean may be likened to the DOD in English. ${ }^{9}$ Song (1993) highlighted the possibility of double accusatives with cwuta "to give," arguing that "dative-shift in English and double-accusativization in Korean are similar so far as both promote a noncore or nonaccusative NP into the position of a core or accusative NP" (p. 41).

Whether the benefactive verbal construction with $c w u$-is the equivalent of the DOD construction in English is not, however, as important as the fact that there are two syntactic forms available in Korean for for-dative verbs. The second is like the PD form in English, as in (11), in which the Goal (or Recipient) is an oblique object.

(11) Mia-ka Yong-ulwihay kulim-ul kuly-ess-ta. Mia-NOM Yong-for picture-ACC draw-PAST-DECL "Mia drew a picture for Yong."

Thus, in Korean there are two forms: (a) the construction with the benefactive $c w u$-, which alternately allows double-accusative structure, as in (8); and (b) the construction with -ulwihay "for" (known in traditional Korean grammar as 
an "adverbializer"; Sohn, 1999), as in (11). We stress here, because it will become important later, that Korean allows the dative alternation with verbs whose English benefactive for analogues do not allow it.

To summarize, English has a dative alternation for a subset of to-dative verbs and a subset of for-dative verbs, where both a prepositional dative form and a double-object form are possible. By contrast, neither Japanese nor Korean permits a double-accusative form with to-datives. As for for-datives, again Japanese prohibits double accusatives, but Korean not only allows double accusatives with this type of verb, it does so very productively (with $c w u$ - as part of the predicate) and hence permits the alternation with more benefactive for-dative verbs than in English. Recall that the dative alternation in English is subject to three constraints: a Broad Range Dative Rule (i.e., the possession constraint), which converts the thematic core of the PD to the thematic core of the DOD; the Narrow Range Dative Rules, which define which verb classes in fact allow the dative alternation; and the Latinate constraint, which makes further delimitations, ruling out particular verbs in these classes. How relevant are these constraints to Japanese and Korean? Bley-Vroman and Yoshinaga (1992, pp. 171-174) argued that a possession constraint can be seen in the Japanese $-n i-o$ construction: Whereas animate NPs marked with -ni can undergo passivization, locative and place NPs marked with -ni cannot. From this they concluded that the former $-n i$ is a dative case marker and the latter $-n i$ is a postposition, and that furthermore this distinction "derives from the possession constraint, since only animates can possess in the relevant sense" (p. 173). Although such a possession constraint may well hold of this $-n i$ and its Korean -eykey counterpart, the point is that there is no Broad Range Rule that converts one thematic core to another. Thus, for all Japanese dative verbs and for Korean to-dative verbs, neither the possession constraint nor the Narrow Range Dative Rules are germane because there is no alternation. As for Korean for-dative verbs, though the Broad Range Dative Rule may be applicable, the Narrow Range Dative Rules are not; verb classes that disallow the alternation in English do allow it in Korean. ${ }^{10}$ In a nutshell, among the three languages under consideration, there are similarities and differences: For to-dative verbs, Japanese and Korean disallow the dative alternation, but English allows it; for for-dative verbs, Japanese disallows alternation, but English and Korean allow it, with Korean being even more permissive than English. These similarities and differences provide an interesting contrast for a study of Japanese and Korean speakers' L2 acquisition of the English dative alternation-in particular, the double-object construction.

\section{THE ENGLISH DATIVE ALTERNATION IN L1 AND L2 ACQUISITION}

As previously mentioned, in contemplating the puzzle of the dative alternation in English, Baker (1979) speculated that it must be that children learn the argument-structure alternations on a conservative, verb-by-verb basis. L1 acquisition studies have challenged this assertion: In the course of development, 
children acquiring English do sometimes produce double-object forms considered illicit in the adult grammar. These are called overgeneralizations. Such DOD overgeneralizations were found in naturalistic data from two children reported on by Bowerman (1988), as well as from five children in the CHILDES database (MacWhinney \& Snow, 1985) in an analysis by Gropen, Pinker, Hollander, Goldberg, and Wilson (1989). Examples include those in (12).

(12) a. You finished me lots of rings. Adam $(4 ; 11)$

b. Jay said me no. Ross $(2 ; 8)$

(Gropen et al., p. 217)

Experimental data reinforce this finding. Mazurkewich and White (1984) tested 22 L1 English-speaking children for knowledge of both the Latinate constraint and the possession constraint. Three groups of children, of 9,12 , and 15 years of age, completed a grammaticality judgment task consisting of alternating and nonalternating to- and for-datives in both the PD and DOD forms. The results showed that these 9-, 12-, and 15-year-olds overgeneralized the DOD to Latinate to-dative verbs, allowing the illicit DOD form at rates of $46.7 \%$, $33.3 \%$, and $11.1 \%$, respectively. Illicit DODs with Latinate for-dative verbs were allowed at the even higher rates of $61 \%$ and $28 \%$ by the 12 - and 15 -year-olds, respectively. They did not, however, overgeneralize to the same degree on sentences violating the possession constraint. The 9-year-olds, for instance, accepted only $18 \%$ of these illicit DOD sentences in contrast to their acceptance of $46.7 \%$ of illicit DOD sentences with Latinate to-dative verbs.

Gropen et al. (1989) also challenged Baker's (1979) conservative-learning proposal for the acquisition of argument-structure alternations. Recall that Baker's solution to the learnability puzzle was that children acquire the dative alternation on a verb-by-verb basis. If this is so, Gropen et al. reasoned, then children should not produce DODs they have never encountered in their input, and thus Gropen et al. put this to the test by using nonce verbs.

In their first study, testing 16 English-speaking children (mean age 7;4), Gropen et al. (1989) introduced nonce verbs using toys and props to provide context. The experimenters primed the children before the experiment by repeatedly eliciting the verb pass in the DOD. They then began a set of "priming blocks," modeling for the subjects the nonce verb in the DOD form while performing a corresponding action. The children were then asked to describe the action using the nonce verb. The same procedure was then used to model the nonce verb in the PD form. The experiment itself directly followed these priming blocks, using the same procedure but with different nonce verbs. Although the results showed a tendency for children to produce the form they heard as the model, there was some productive use of the DOD by these children: When the nonce verbs were modeled in the PD form, the DOD was produced $30 \%$ of the time (pp. 231-232). Thus, Gropen et al. concluded that children are not strictly conservative.

In a similar, second experiment, Gropen et al. (1989) tested a different group of 32 children (age range $5 ; 8$ to $8 ; 11$ ) for knowledge of the possession 
constraint. This experiment contrasts with the first in that each nonce verb was tested with three different recipients: the child, an animate toy, or an inanimate toy (this last considered not to be a potential possessor). Like in the first experiment, the experimenter performed an action, but this time the nonce verb was introduced in a neutral gerund form (i.e., there was no modeling of the DOD or the PD). The results showed that the children produced the DOD the most when they themselves were the recipient, at a mean rate of $52 \%$, followed by $38 \%$ for animate toy recipients and $32 \%$ for inanimate toy recipients. These results bolster the conclusion from the first experimentnamely, that children are not conservative in regard to the DOD. (Gropen et al. furthermore interpreted these results as evidence of knowledge of the possession constraint on the part of these children.)

Recent studies on L2 acquisition of the English dative alternation have also made use of nonce verbs. Bley-Vroman and Yoshinaga (1992) asked whether adult L2 acquirers (a) have knowledge of the possession constraint and (b) are able to acquire the Narrow Range Dative Rules proposed by Pinker (1989). The study was grounded in the Fundamental Difference Hypothesis (BleyVroman, 1990), which posits that the sole source of UG-derived knowledge for the L2 adult is the L1 grammar. Bley-Vroman and Yoshinaga hypothesized that Japanese acquirers of English will "successfully acquire (more accurately, transfer from Japanese) the possession constraint on the double-object dative" (p. 174). By contrast, language-specific constraints such as the Narrow Range Rules, "which also have their basis in universal grammar," are hypothesized not to be acquirable because these "may well not be uniformly available to adult second language learners" (p. 167, but see fn. 10).

The first of the Bley-Vroman and Yoshinaga (1992) experiments tested for knowledge of the possession constraint. Sixty-four native English speakers and 66 advanced Japanese speakers of English were given brief written paragraphs that included a nonce verb in the PD form. In some paragraphs the nonce verb involved possession, whereas in others it did not. Following the paragraphs were the test sentences containing the nonce verb, in both the DOD and PD forms, whose grammaticality the subjects were asked to judge. The results showed that both groups accepted the (licit) possessive DOD sentences and rejected the (illicit) nonpossessive DOD sentences. Bley-Vroman and Yoshinaga concluded that these advanced L2 speakers of English were able to discern the possession constraint much like the native speakers.

Eighty-five native English speakers and 85 Japanese acquirers of English participated in a second experiment. The same procedure was used, designed this time to ascertain knowledge of Narrow Range Rules (NRRs); the only difference from the first experiment was the testing of real verbs in addition to nonce verbs. The real and nonce dativizable NRRs that were tested were of the tell-type ("illocutionary communication"), the throw-type ("instantaneous causation of ballistic motion"), and the send-type ("transfer of possession mediated by separation in time and space"). The real and nonce nondativizable 
NRRs tested were of the push-type ("continuous causation of accompanied motion in some manner") and the whisper-type ("manner of speaking").

The results for the real verbs indicated that both groups accepted licit DODs and rejected illicit DODs. Thus, native and nonnative speakers correctly distinguished between alternating and nonalternating real verbs. The picture was different, however, with nonce verbs, where the difference in means between alternating and nonalternating verbs for the native speakers was statistically significant but that of the nonnative speakers was not: Whereas both groups rejected (illicit) DODs with nonalternating nonce verbs, only the native speakers accepted (licit) DODs with alternating nonce verbs. Bley-Vroman and Yoshinaga (1992) concluded that these Japanese speakers had not acquired the English Narrow Range Dative Rules that determine whether a nonce verb alternates. They further concluded that the combined results of the two experiments supported the Fundamental Difference Hypothesis, as these advanced L2 adults knew the possession constraint but failed to acquire the language-specific NRRs. ${ }^{11}$

Curiously absent from the discussion of the second experiment is the issue of transfer. The Fundamental Difference Hypothesis posits transfer from the L1 as a possible source of knowledge for adult L2 acquisition. In their description of Japanese, Bley-Vroman and Yoshinaga (1992) maintained that the -ni $-o$ construction equates with the English DOD, not the PD form (but see fn. 6). If this equivalence is correct, then, based on the Fundamental Difference Hypothesis, transfer effects are expected. The $-n i-o$ construction is shown in (13), this time employing a verb that disallows the DOD in English.

(13) Hanako-ga Taro-ni nanika-o sasayai-ta. Hanako-NOM Taro-to/DAT something-ACC whispered-PAST

"Hanako whispered something to Taro." （based on Inagaki's [13], 1997, p. 644)

Recall that, according to Bley-Vroman and Yoshinaga (1992), the relevant property of what they take to be the Japanese DOD is the possession constraint, not NRRs (but see the discussion of Inagaki, 1997, later in this section). Hence, on their account, given that these $-n i-o$ forms are DODs, then as long as English DOD forms abide by the possession constraint, L1 Japanese speakers should accept them, including illicit ones, such as the English DOD analogue to (13). Not only did they not do this, they also tended to reject the English DOD with nonce verbs, both alternating and nonalternating. It thus appears that Bley-Vroman and Yoshinaga are faced with a dilemma: Either there is no transfer of the possession constraint as realized in Japanese, or the -ni $-o$ construction is not to be equated with the English DOD construction but rather with the PD construction.

Another L2 study of the English dative alteration, this time contrasting adult Chinese and Japanese acquirers, is Inagaki (1997). Inagaki sought to investigate the issue of transfer in this domain. According to Huang (1994, cited 
in Inagaki), Chinese exhibits the dative alternation with certain verb classes. Specifically, Chinese is like English both for tell-type verbs (which alternate) and for whisper-type verbs (which do not), the latter appearing only as prepositional datives. Yet unlike English, which allows the alternation with throwtype but not push-type verbs, Chinese allows neither type to alternate; both occur only in the PD form. Adopting the Fundamental Difference Hypothesis, Inagaki predicted that Chinese acquirers of English would (a) accept the DOD with tell-type verbs but reject it with whisper-type verbs, and (b) be unable to distinguish between (licit) throw-type DODs and (illicit) push-type DODs.

As for Japanese, Inagaki (1997) maintained that, although it has no dative alternation, an NRR does play a role in regard to (only) one verb class, that of "continuous causation of accompanied motion," that is, the push-type. According to Inagaki, this is the only class of verbs in Japanese that does not occur in the $-n i-o$ construction. ${ }^{12}$ He additionally maintained, like Bley-Vroman and Yoshinaga (1992), that the Japanese -ni -o construction is equivalent to the English DOD (see fn. 6). That the push-type and throw-type verb classes are "delineated in relation to the ability to occur in the DOD construction" is, according to Inagaki, "evidence for the direct application of the [NRR] to the DOD construction" (p. 644). As such, knowledge of the NRR relevant to the push-type verb class is hypothesized under the Fundamental Difference Hypothesis to transfer, leading L1 Japanese speakers to make the (targetlike) distinction between push- and throw-type verbs in English. Thus, Japanese acquirers of English were hypothesized to (a) know that the DOD is illicit with push-type verbs but licit with throw-type verbs and (b) be unable to distinguish between (licit) tell-type DODs and (illicit) whisper-type DODs.

Inagaki (1997) employed the same procedures as in the second experiment of Bley-Vroman and Yoshinaga (1992) described earlier in this section. The results showed that 32 advanced adult Japanese speakers were able to distinguish between real and nonce tell-type verbs and whisper-type verbs in English, correctly accepting DODs with the former and rejecting them with the latter. These results contrast with those of the push-and throw-type verbs; they rejected DODs with (licit) real and nonce throw-type verbs as well as with (illicit) real and nonce push-type verbs, thereby revealing failure to distinguish them. The native speaker group correctly distinguished between DODs of (licit) real throw-type verbs and (illicit) real push-type verbs, but they, too, failed to distinguish between DODs of (licit) nonce throw-type verbs and (illicit) nonce push-type verbs, accepting DODs with both. In sum, for the English DOD form, the L1 Japanese speakers-contrary to both of Inagaki's predictions-did distinguish between (real and nonce) tell- and whisper-type verbs but not (real and nonce) push- and throw-type verbs, whereas the native speakers distinguished between real push-and throw-type verbs but not nonce push- and throw-type verbs.

Inagaki (1997) conceded that the Japanese group's results contradict the transfer assumption of the Fundamental Difference Hypothesis (at least as conceptualized by Inagaki). He concluded that L2 adults must rely purely on 
frequency in the input to learn these verbs one by one, speculating that these subjects have not been exposed to a high enough incidence of push- and throw-type verbs to be able to make the distinction. There is, however, an alternative to rejecting the idea of transfer: Perhaps these L2 results are again an indication, as we suggested previously, that the -ni -o construction in Japanese is equivalent to the PD construction in English, not the DOD. If Japanese had a DOD (with whatever verb classes), then transfer would lead one to expect Japanese speakers to accept the English DOD (with analogous verb classes).

Interestingly, unambiguous support for L1 transfer comes from the results of the 32 adult Chinese speakers in Inagaki's (1997) study. Recall that Chinese has both forms of the dative alternation only with tell-type verbs; the other verb types tested allow only the PD. The Chinese speakers' results showed a statistically significant difference between acceptance of (licit) DODs with real and nonce tell-type verbs and rejection of (illicit) DODs with real and nonce whisper-type verbs. In contrast, there was no statistically significant difference between DODs of real and nonce throw- and push-type verbs. Thus, there is evidence of transfer from the L1 for these Chinese speakers of English.

Evidence of L1 influence has also been found going the other way-that is, where the L1 has the dative alternation but the target language does not. White (1987) tested English-speaking children $(n=120)$ and adults $(n=27)$ acquiring French, which only has the PD form. Using a grammaticality judgment task, she found that both child and adult subjects readily accepted (illicit) double-object forms in French. This result was confirmed in a preference-task experiment (White, 1991) testing 55 English-speaking children acquiring French. In each of these studies, White concluded that the double-object form transfers from L1 English to French Interlanguage.

In sum, what the L2 acquisition literature indicates is clear evidence of transfer in relation to the dative alternation. However, L2 studies of other argument-structure alternations suggest that the issue of L1 influence may not be as straightforward as has been generally conceived. Montrul (1997) argued that overt derivational morphology may play a key role in understanding how the L1 grammar (sometimes) affects the L2 acquisition of syntactic argument structure. One of Montrul's studies investigated L1 Spanish and L1 Turkish speakers' acquisition of the English causative-inchoative alternation, illustrated in (14).

$\begin{array}{ll}\text { (14) a. Georgie broke the window. } & \text { (causative) } \\ \text { b. The window broke. } & \text { (inchoative) }\end{array}$

English, Spanish, and Turkish differ in regard to this alternation. As shown in (14), no overt morphology marks either form in English. In contrast, the Spanish inchoative must be marked by the reflexive clitic, se in (15b), the effect of which is to "detransitivize" the causative, in (15a). Without the reflexive clitic, as in (15c), the inchoative is ungrammatical. 
(15) a. María rompió los vasos. Maria broke the glasses

b. Los vasos se rompieron the glasses REFL broke

"The glasses broke."

c. *Los vasos rompieron. the glasses broke

(Montrul's [20], p. 44)

Turkish differs from both English and Spanish. For some verbs, the inchoative in Turkish is like in Spanish: An overt morpheme, the verbal suffix - $l$, is required, as in (16b), to detransitivize the causative, in (16a). Again, without this verbal suffix, as in (16c), the inchoative is not well formed.

(16) a. Hirsiz pencere-yi kur-dl.

thief window-ACC break-PAST

"The thief broke the window."

b. Pencere kir-ll-dl. window break-PASS-PAST

"The window broke."

c. *Pencere kur-dl.

window break-PAST

(Montrul's [22], p. 46)

Most verbs in Turkish, however, realize yet another causative-inchoative pattern: It is the causative form, as in (17a), that requires the morphological marker, whereas a marker is prohibited in the inchoative. This is shown in the comparison between (17b), which lacks the detransitivizer - $l$ l found in (16b), and the ungrammatical (17c), which does have it.

(17) a. Düşman gemi-yi bat-ır-mış.

enemy ship-ACC sink-CAUS-PAST

"The enemy sank the ship/made the ship sink." (Montrul's [21b], p. 45)

b. Gemi bat-mıs.

ship sink-PAST

"The ship sank."

c. *Gemi bat-Il-mis

ship sink-PASS-PAST

(Montrul's [21a], p. 45)

(adapted from Montrul's [24], p. 47)

To summarize, in regard to the realization of the inchoative form, English has no overt morphological marker (14b), Spanish does (15b), and Turkish does for some verbs (16b) but does not for others (17b).

Montrul (1997) was interested in the effect of the L1 realization of the inchoative-specifically in regard to presence versus absence of morphological markers-on the L2 acquisition of the inchoative. In her L2 English study, there were 18 early-intermediate L1 Turkish speakers (age range 14-22 years) and 29 intermediate and advanced L1 Spanish speakers (age range 15-17 years). One of the data-collection methods was a picture judgment task depicting either an agent acting on an object (causative) or just the result of that action (inchoative). Each picture was accompanied by a pair of sentences to 
be judged. In the pictures with an agent, the two sentences were always transitive, and in the pictures without an agent, they were always intransitive. The results show a definite (and statistically significant) L1 effect: Only the Turkish speakers (correctly) accepted the contextually licit inchoative sentences; that is, the Spanish speakers had not acquired the inchoative form in English.

Montrul (1997) attributed the discrepancy between the Spanish speakers and the Turkish speakers to the difference in the representations of inchoatives in their respective L1s. Specifically, Spanish requires overt morphology to license the inchoative, whereas Turkish has both overtly marked and nonovertly marked inchoative forms. This, according to Montrul, is what accounted for the difference in their L2 English. The absence of overt marking on the English inchoative causes the Spanish speakers to reject it because in their L1 an overt morphological marker is required, but the Turkish speakers, in contrast, can rely on their L1 to accept it because Turkish does have a nonovertly marked inchoative, similar to that of English.

To summarize the acquisition literature pertinent to our study: Montrul (1997) proposed that L1 transfer at the level of (derivational) morphology often sees its effects at the level of L2 syntax; the precise shape of the effects depends on the relevant properties of the source and target languages. Transfer effects have been found in L2 studies involving the English dative alternation, both as the target language and as the source language, but none of these studies addressed the issue of morphological licensing. Finally, studies of L1 English acquisition of the dative alternation indicate that children tend to sometimes overextend DODs until the Latinate constraint and the NRRs are acquired. These findings should be kept in mind because our child L2 study probes the interplay between, on the one hand, the L1 influence common in adult $\mathrm{L} 2$ acquisition and, on the other, the overgeneralization documented in L1 acquisition.

\section{THE STUDY}

\section{Hypotheses}

Full Transfer posits that the initial states of L2 acquirers with different L1s will be distinct from each other in areas where their L1s are distinct. Crucially, developmental differences are expected precisely because the starting points for L2 acquisition are different. The insights of Montrul (1997), however, raise the issue of the level of grammar implicated in transfer (i.e., syntax, morphology, or both) from which contrasting predictions ensue. Finally, recall that beyond the L2 initial state, Full Access posits UG-constrained restructuring when the input cannot be accommodated by the current state of the Interlanguage. In the case at hand, Full Access predicts that during the course of L2 development there will be behavior like that found in L1 acquisition-that is, overgeneralization of the English double-object form. It is important to underscore that in regard to the phenomena under study here, the predictions stemming 
Table 1. Double objects in English, Japanese, and Korean

\begin{tabular}{|c|c|c|}
\hline \multirow[b]{2}{*}{ Language } & \multicolumn{2}{|c|}{ Sentence type } \\
\hline & To-dative double objects & For-dative double objects \\
\hline English & $\begin{array}{l}\text { Yes, but restricted by the posses- } \\
\text { sion constraint, the Latinate con- } \\
\text { straint, and Narrow Range Rules }\end{array}$ & $\begin{array}{l}\text { Yes, but restricted by the posses- } \\
\text { sion constraint, the Latinate con- } \\
\text { straint, and Narrow Range Rules }\end{array}$ \\
\hline Japanese & No & No \\
\hline Korean & No & $\begin{array}{l}\text { Yes, but only if the } c w u \text { - mor- } \\
\text { pheme is present }\end{array}$ \\
\hline
\end{tabular}

from Full Transfer and Full Access may at times be directly at odds. This is because the two parts of the model point to different expectations as L2 development unfolds, and thus subjects could produce evidence for either Full Transfer or Full Access depending on their developmental stage.

To understand the specific predictions of the hypotheses, it is essential to appreciate the similarities and differences among the languages in question. These are summarized in Table 1. To recapitulate, Japanese prohibits double objects with all dative verbs, but Korean disallows them only with to-dative verbs; with for-dative verbs, Korean productively licenses double objects by the $c w u$ - morpheme. Based on these facts, Full Transfer assumes that for the L1 analogues of to-datives the L2 initial states of Japanese and Korean speakers are the same, but for the L1 analogues of for-datives their L2 initial states differ. Thus, it is only with for-dative verbs that we would expect to find developmental differences between the two groups in their L2 acquisition of English double objects.

Our first hypothesis, stated in (18), concerns the predicted similarity for Japanese and Korean speakers in the L2 development of double objects with to-dative verbs.

(18) Hypothesis 1

With regard to to-dative verbs in L2 English,

a. Full Transfer: Japanese and Korean children will (initially) be restrictive, disallowing double-object forms.

b. Full Access: Japanese and Korean children will (later) overgeneralize, as in L1 English acquisition.

Note that the question of the level of grammar at which transfer operates is irrelevant here because double objects are not allowed with the analogue todative verbs in either Japanese or Korean. In other words, there is no doubleobject structure in the L1s to transfer (and so in this respect their L2 initial states are like the initial state of children acquiring English as a native language). The prediction here, then, is that Japanese- and Korean-speaking children will, owing to L1 influence, initially accept only the PD form of to-dative 
verbs; as they begin to encounter DOD forms in the input, they will come to acquire double objects with such verbs in the same way L1 English-acquiring children do. In other words, they should start out restrictive (i.e., disallowing double objects with to-dative verbs) and subsequently allow overgeneralization.

The same rationale extends to the acquisition of for-datives by the Japanese speakers. Because Japanese disallows double objects with for-dative verbs, again the prediction is that Japanese-speaking children will start out restrictive and later overgeneralize DODs with for-dative verbs, like L1 Englishacquiring children do, as stated in (19).

(19) Hypothesis 2

With regard to for-dative verbs in L2 English,

a. Full Transfer: Japanese children will (initially) be restrictive, disallowing doubleobject forms.

b. Full Access: Japanese children will (later) overgeneralize, as in L1 English acquisition.

As for the Korean speakers' acquisition of for-dative verbs, here Montrul's (1997) work on L1 influence is relevant, giving rise to two distinct hypotheses. The first relates to the possibility that the mere existence of double-object structure in Korean for-dative verbs will lead to general acceptance of doubleobject for-datives in English. We refer to this as "transfer of syntax" (hypothesis 3 in [20]). The other possibility is that overt (derivational) morphology does play a role in transfer. Specifically, given that Korean $c w u$ - morphologically licenses double objects with for-dative verbs, this will lead to (initial) disallowance of double-object for-datives in English because English has no overt morphological licensor. We refer to this as "transfer of morphology" (hypothesis 4 in [21]). Note that in the latter case, although the hypothesized initial prohibition is expected to be later overridden on the basis of positive evidence (i.e., double-object exemplars in the input), there is no expectation that development should proceed as in L1 acquisition, precisely because something in the L1 grammar does transfer.

(20) Hypothesis 3

Transfer of syntax: With regard to for-dative verbs in L2 English, Korean children will overgeneralize from the beginning.

(21) Hypothesis 4

Transfer of morphology: With regard to for-dative verbs in L2 English, Korean children will initially be restrictive with double-object forms.

According to hypothesis 3 (transfer of syntax), because Korean permits double objects with a wider range of for-dative verbs than does English, Korean speakers should permit (licit and illicit) for-dative double objects in English (i.e., overgeneralize right from the start). By contrast, according to hypothesis 4 (transfer of morphology), because Korean requires an overt mor- 
Table 2. Double-object behavior of test verbs in English and their analogues in Korean

\begin{tabular}{lcc}
\hline & $\begin{array}{c}\text { Do not occur } \\
\text { with double objects } \\
\text { in Korean }\end{array}$ & $\begin{array}{c}\text { Occur with } \\
\text { double objects } \\
\text { in Korean } \\
\text { (licensed by cwu-) }\end{array}$ \\
\hline $\begin{array}{l}\text { Occur with double objects } \\
\text { in English }\end{array}$ & $\begin{array}{l}\text { bring to } \\
\text { hand to } \\
\text { send to } \\
\text { show to } \\
\text { throw to }\end{array}$ & $\begin{array}{l}\text { buy for } \\
\text { fraw for }\end{array}$ \\
find for \\
in English & $\begin{array}{l}\text { explain to } \\
\text { repeat to } \\
\text { say to }\end{array}$ & finish for \\
fix for & hold for \\
shout to & keep for \\
whisper to & watch for \\
\hline
\end{tabular}

${ }^{\text {a }}$ The use of fix (for) was in the sense of repair, not prepare, as the latter usage permits the DOD construction. In the experiment, the context ensured the desired interpretation of the test sentences: The sheep's fire engine broke down and the giraffe was able to repair it for the sheep.

phological licensor of double objects with for-dative verbs, Koreans should start out disallowing (licit and illicit) for-dative double objects in English because English does not morphologically license them. Hypotheses 3 and 4, then, are in direct opposition.

The verbs used in the experiment were chosen on the basis of their ability to alternate in English and Korean (recall that no verbs allow the doubleobject construction in Japanese). Attempts were also made to choose verbs that the children would know. As Latinate verbs are said to be acquired relatively late by native speakers, they were avoided, with the exception of $e x$ plain, finish, and repeat, verbs considered common to child vocabulary. Table 2 lists the test verbs; all of them occur in the PD form in the three languages at issue, so Table 2 is restricted to their double-object behavior in English and Korean. The test sentences were submitted to verification by speakers of the local variety of English (see Appendix A). The Japanese and Korean analogues were evaluated by native speaker consultants; their judgments are given in Appendix B.

\section{Subjects}

Three groups of children participated in this study: six L1 English speakers, five L1 Japanese speakers, and five L1 Korean speakers. ${ }^{13}$ Relevant details are summarized in Table 3, where the subjects are ordered by age within their language groups.

The native English-speaking children are all monolingual. They were tested individually in their homes, with the exception of one who was tested in a 
Table 3. Subject details

\begin{tabular}{cccc}
\hline Subjects & Age & Sex & $\begin{array}{r}\text { Years of } \\
\text { exposure }\end{array}$ \\
\hline English & & & \\
CB & $6 ; 11$ & M & - \\
VA & $7 ; 6$ & F & - \\
DD & $8 ; 4$ & F & - \\
HC & $9 ; 0$ & F & - \\
MH & $9 ; 4$ & F & - \\
NB & $10 ; 10$ & F & - \\
Japanese & & & \\
MS & $7 ; 3$ & F & $2 ; 11$ \\
RN & $7 ; 5$ & F & $1 ; 3$ \\
CO & $7 ; 6$ & F & $3 ; 4$ \\
CS & $8 ; 9$ & F & $2 ; 3$ \\
TN & $8 ; 11$ & M & $1 ; 3$ \\
Korean & $6 ; 6$ & M & $2 ; 11$ \\
HW & $7 ; 10$ & M & $2 ; 4$ \\
BC & $7 ; 10$ & F & $2 ; 10$ \\
CM & $9 ; 1$ & M & $1 ; 0$ \\
WS & $10 ; 2$ & M & $3 ; 11$ \\
HEC & & & \\
\hline
\end{tabular}

university classroom. The Japanese subjects were tested individually during the school hours of a local Japanese Saturday school. ${ }^{14}$ The data collection from the Korean children was conducted in their homes, individually. ${ }^{15}$

At the time of testing, all of the subjects attended British elementary schools in the Northeast of England. The L2 children were acquiring English through naturalistic input from friends and at school (i.e., none had had explicit lessons in English as an L2). The language of the home, on the other hand, was exclusively the L1. When the children began school in England, their parents continued to communicate with them in the L1. As shown in Table 3 , there is a range in age and years of exposure among the subjectsalthough it is noteworthy that all the L2 children had had at least a year of exposure to English prior to the study. As would be expected, there was also a range in English proficiency among the nonnative speakers. The issue of determining relative L2 proficiency will be discussed in the Results section.

\section{Materials}

A variety of props was used to enact short stories designed to provide a specific context for the test sentences. These included four plastic animals (a pig, a sheep, a tiger, and a giraffe) and a set of miniature dishes, including two each of spoons, forks, plates, and cups. Other materials comprised an assort- 
ment of marbles, a set of eight miniature storybooks, a wooden car, a wooden fire engine, two coins, and some crayons. For the nonnative speakers, there were also three pictures for the picture description task.

\section{Procedures}

As this study involved two groups of nonnative speakers with distinct L1s, it was necessary to attempt to determine comparability among the children with regard to their L2 English. Moreover, because transfer effects are expected to be particularly robust in lower levels of L2 proficiency, it was necessary to somehow rank the nonnative subjects. Pictures were therefore used to elicit natural speech for the purpose of ascertaining English proficiency. The pictures also served to help the children relax. After the picture description task, each child was asked to name all the toys to be used as props. Most children had no difficulty with this, with the rare exception of having to be told the word for "fire engine." The researcher then introduced the oral grammaticality judgment task of McDaniel and Cairns $(1990,1996)$, closely following their procedures. $^{16}$

Step 1. The child was told, "We're going to talk about the way we say things in English." Pointing to the solitary pig, the experimenter said, "Listen to how I say this in English. This is a pigs," followed by "Is this the right way to say it, or does it sound funny?" Similar simple examples were given. All of the utterances presented to the children to judge were spoken following a short scenario using the toys. We maintain that context is often crucial for making grammaticality judgments, particularly in the case of children. By providing context, the experimenter can be confident that the particular sentence will be evaluated against that particular context, leaving little room for other interpretations.

Step 2. To make sure the subjects understood the task, they were given practice sentences. Like the presentation of the target sentences (step 4), these were presented as minimal pairs to better ensure that any potential rejection would be based on grammar rather than other factors. Following a brief scenario, then, the child was presented with the first sentence of the pair. Throughout the entire test, each sentence was given separately, and the second of the two test sentences was uttered only after the first sentence had been judged. For the practice sentences, coaching and explanation were readily given. Examples of pairs of practice sentences are provided in (22)(24).

(22) a. The pig is touching the tiger. b. *The pig is the tiger touching.

(23) a. *The tiger on head spoon has. b. *The tiger head spoon has on. 
(24) a. The sheep and the pig are running.

b. The sheep and the pig are running with each other.

After the child had attempted five such minimal pairs or had correctly answered three minimal pairs in a row, he or she moved on to the pretest sentences.

Step 3. The pretest sentences differed from the practice sentences in that there was no longer any coaching or explanation given to the child; instead, every response was accepted with a simple word of encouragement. These sentences were similar to the practice sentences. ${ }^{17}$ To advance to the target sentences, the child was required to give three correct responses in a row.

Step 4. The target sentences were then presented, again in the context of brief stories. It was thought that seeing the action characterized by the test sentence would highlight adherence to the possession constraint, avoiding the possibility that a DOD sentence would be rejected due to perceived violation of this constraint. Furthermore, in recognition of the importance of animacy in the possession constraint, all participants in the stories were toy animals. An example of one scenario is given in (25).

(25) Pig: I'm so thirsty. I really need a cup of tea. But I'm just a little pig. I don't know how to make tea.

Giraffe: Oh, I know how. My Mum taught me how. I'll do it. (The giraffe puts the cup on the saucer, stirs the tea, and gives it to the pig.)

Giraffe: There you go.

Pig: Thanks!

Following each scenario, the child was presented with the first of a minimal pair of sentences. As illustrated in (26), the only difference between them was DOD versus PD. ${ }^{18}$

(26) a. The giraffe made the pig a cup of tea.

b. The giraffe made a cup of tea for the pig.

To control for ordering biases, the sentence pairs were randomly ordered, with half of the pairs beginning with the DOD form and the other half beginning with the PD form. Additionally, two versions of the test, each with a different random order, were used. The target sentences totaled 30 minimal pairs, representing five tokens of six sentence types..$^{19}$ Owing to the reality of time constraints (and attention spans), children were retained in the study if they were able to judge the first three tokens of each of the six types. For comparability, these tokens were always presented in the first half of the session, still in random order. Last, filler sentences were used throughout the task as needed to break up the pattern of responses, to provide a variety of sentence structures, and, at times, to determine whether the child was still 
paying attention. If a child completed the entire test (and many did not), it took about an hour; otherwise the session would last about 40 minutes. The children generally seemed to enjoy themselves.

\section{RESULTS}

\section{Picture Description Task}

Assessing the L2 proficiency of the nonnative subjects was complicated by their young age. Likewise, the traditional (written) cloze test often used in adult L2 studies was clearly inappropriate. The L1 practice of using mean length of utterance (MLU) seemed inadequate as the sole measure of development because the majority of the children were beyond the three- to fourword stage. Therefore, an L2 proficiency score was devised by measuring both language complexity and grammatical accuracy.

The complexity measure is a word-based MLU, reflecting the average number of words per utterance. The first step in its calculation was to count the total number of words uttered in the picture description task. Each transcript was then separated into utterances. The definition of utterance was taken from a practice reported in Slobin (1993). ${ }^{20}$ The total number of words was then divided by the total number of utterances.

The accuracy measure reflects the rate of error-free utterances. There were three basic types of errors: syntactic, morphological, and lexical-idiomatic. A practice devised by Larsen-Freeman (1983) of counting error-free segments was adapted, wherein we defined segment as the utterance. ${ }^{21}$ An utterance that contained even one error was discounted, leaving only error-free utterances. The number of error-free utterances was then divided by the total number of utterances, resulting in a percentage of error-free utterances.

It was assumed that a more valid indicator of proficiency would be provided by a combination of the two measures. First, to make them equivalent, the accuracy measure (a percentage) was converted into a decimal figure by multiplying by 10 (e.g., $11.1 \% \times 10=1.11$ ). Second, the ranges of each measure had to be correlated. The range for the (converted) accuracy measure (at 7.64) was 1.6 times the range of the complexity measure (at 4.8 ). Therefore, the complexity measure for each child was multiplied by 1.6. This figure was then added to the (converted) accuracy measure figure, resulting in a single proficiency score for each child. These results are shown in Table 4, in which the children are ranked by proficiency score within language group. As seen in Table 4, the proficiency scores of the subjects from both language groups are comparable. A one-way ANOVA shows there is no significant difference between the two groups, $F(1,8)=0.132, p=.726$.

\section{Prepositional Dative Sentences}

The acceptance rate for the PD form across all three groups is consistently high, with individual subject totals, as shown in the last column of Table 5, 
Table 4. Measures of L2 English proficiency

\begin{tabular}{|c|c|c|c|c|c|c|}
\hline Subjects & Words & Utterances & $\begin{array}{l}\text { Complexity } \\
\text { measure }^{\mathrm{a}}\end{array}$ & $\begin{array}{l}\text { Error-free } \\
\text { utterances }\end{array}$ & $\begin{array}{l}\text { Accuracy } \\
\text { measure }^{b}\end{array}$ & $\begin{array}{l}\text { Proficiency } \\
\text { score }^{c}\end{array}$ \\
\hline \multicolumn{7}{|l|}{ Japanese } \\
\hline RN & 31 & 9 & 3.4 & 1 & $11.1 \%$ & 6.55 \\
\hline $\mathrm{TN}$ & 74 & 17 & 4.4 & 3 & $17.6 \%$ & 8.80 \\
\hline $\mathrm{CO}$ & 22 & 7 & 3.1 & 5 & $71.4 \%$ & 12.10 \\
\hline MS & 38 & 8 & 4.8 & 7 & $87.5 \%$ & 16.43 \\
\hline $\mathrm{CS}$ & 66 & 13 & 5.1 & 11 & $84.6 \%$ & 16.62 \\
\hline \multicolumn{7}{|l|}{ Korean } \\
\hline $\mathrm{BC}$ & 41 & 17 & 2.4 & 5 & $29.4 \%$ & 6.78 \\
\hline HW & 48 & 14 & 3.4 & 9 & $64.3 \%$ & 11.87 \\
\hline $\mathrm{CM}$ & 63 & 11 & 5.7 & 5 & $45.5 \%$ & 13.67 \\
\hline WS & 59 & 14 & 4.2 & 10 & $71.4 \%$ & 13.86 \\
\hline HEC & 72 & 10 & 7.2 & 8 & $80.0 \%$ & 19.52 \\
\hline
\end{tabular}

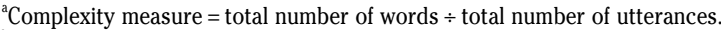

${ }^{\mathrm{b}}$ Accuracy measure $=$ total number of error-free utterances $\div$ total number of utterances

${ }^{c}$ Proficiency score $=($ complexity measure $\times 1.6)+($ accuracy measure $\times 10)$.

Table 5. Response by individuals to all prepositional dative (PD) sentences

\begin{tabular}{|c|c|c|c|}
\hline Subjects & $\begin{array}{l}\text { Correctly accepted PD } \\
\text { with to-dative verbs } \\
(\text { e.g., sent } X \text { to } Y)^{\mathrm{a}}\end{array}$ & $\begin{array}{l}\text { Correctly accepted PD } \\
\text { with for-dative verbs } \\
(\text { e.g., found } X \text { for } Y)^{\mathrm{b}}\end{array}$ & Total PDs accepted \\
\hline \multicolumn{4}{|l|}{ English } \\
\hline $\mathrm{CB}$ & $8 / 8 \quad(100 \%)$ & $5 / 7 \quad(71.4 \%)$ & $13 / 15 \quad(86.7 \%)$ \\
\hline VA & $8 / 10 \quad(80 \%)$ & $9 / 10 \quad(90 \%)$ & (85\%) \\
\hline DD & $10 / 10(100 \%)$ & $10 / 10(100 \%)$ & $20 / 20 \quad(100 \%)$ \\
\hline $\mathrm{HC}$ & $10 / 10(100 \%)$ & 10/10 (100\%) & $20 / 20 \quad(100 \%)$ \\
\hline $\mathrm{MH}$ & $10 / 10(100 \%)$ & $10 / 10(100 \%)$ & $20 / 20 \quad(100 \%)$ \\
\hline NB & $10 / 10(100 \%)$ & $10 / 10(100 \%)$ & $20 / 20 \quad(100 \%)$ \\
\hline Total & $56 / 58(96.6 \%)$ & $54 / 57(94.7 \%)$ & $110 / 115(95.7 \%)$ \\
\hline \multicolumn{4}{|l|}{ Japanese } \\
\hline $\mathrm{RN}$ & $10 / 10(100 \%)$ & $9 / 9 \quad(100 \%)$ & $19 / 19 \quad(100 \%)$ \\
\hline $\mathrm{TN}$ & $8 / 10 \quad(80 \%)$ & $8 / 9 \quad(88.9 \%)$ & $16 / 19(84.2 \%)$ \\
\hline $\mathrm{CO}$ & $6 / 6 \quad(100 \%)$ & $6 / 7 \quad(85.7 \%)$ & $12 / 13 \quad(92.3 \%)$ \\
\hline MS & $5 / 7 \quad(71.4 \%)$ & $6 / 6 \quad(100 \%)$ & $11 / 13 \quad(84.6 \%)$ \\
\hline $\mathrm{CS}$ & $7 / 7 \quad(100 \%)$ & $7 / 7 \quad(100 \%)$ & $14 / 14 \quad(100 \%)$ \\
\hline Total & $36 / 40 \quad(90 \%)$ & $36 / 38(94.7 \%)$ & $72 / 78 \quad(92.3 \%)$ \\
\hline \multicolumn{4}{|l|}{ Korean } \\
\hline $\mathrm{BC}$ & $5 / 6 \quad(83.3 \%)$ & $4 / 6 \quad(66.7 \%)$ & $(75 \%)$ \\
\hline HW & $8 / 8 \quad(100 \%)$ & $4 / 7 \quad(57.1 \%)$ & $(80 \%)$ \\
\hline $\mathrm{CM}$ & $9 / 10 \quad(90 \%)$ & $10 / 10(100 \%)$ & $(95 \%)$ \\
\hline WS & $9 / 10 \quad(90 \%)$ & $10 / 10(100 \%)$ & $(95 \%)$ \\
\hline HEC & $10 / 10(100 \%)$ & $10 / 10(100 \%)$ & $20 / 20 \quad(100 \%)$ \\
\hline Total & $41 / 44(93.2 \%)$ & $38 / 43(88.4 \%)$ & $79 / 87 \quad(90.8 \%)$ \\
\hline
\end{tabular}

a.g., The sheep sent the book to the pig.

b.g., The tiger found a spoon for the sheep. 
ranging from $75 \%$ to $100 \%$. Like all of the following tables, Table 5 reports both raw numbers and percentages for each subject as well as for each group; the L1 English subjects are ordered by age, whereas the nonnative subjects are ordered according to ascending proficiency score.

From Table 5 we can see that native and nonnative subjects alike had little trouble with prepositional datives. A one-way ANOVA shows no significant difference between the Japanese and Korean groups for PDs with either to-dative verbs, $F(1,82)=0.119, p=.739$, or for-dative verbs, $F(1,79)=1.039, p=.338$. Interestingly, at least one subject from each language group rejected the verb to watch (The pig watched the marble for the giraffe). Perhaps the context provided was not felicitous: The pig agreed to keep an eye on the giraffe's (valuable) marble while the giraffe went away on holiday. This single verb accounts for 4 of the rejected 18 licit PD forms. No other single verb in the PD form was rejected by more than two subjects.

\section{Double-Object Sentences}

To-Dative Sentences. Table 6 provides the breakdown of responses by individual subjects to the DOD form of the to-dative sentences (e.g., The tiger handed the giraffe the fork; * The tiger explained the pig the answer). For these to-dative sentences, there is evidence of overgeneralization from the L1 English-speaking children. Although it is expected that L1 subjects will generally accept licit DOD forms, acceptance of illicit DODs is evidence for overgeneralization because these forms could not have been heard in the input. The mean acceptance of $37.9 \%$ of illicit DOD forms (middle column) replicates the findings of overgeneralization in the L1 English literature, discussed previously (Bowerman, 1988; Gropen et al., 1989; Mazurkewich \& White, 1984).

The nonnative subjects also overgeneralize, accepting illicit DOD forms. The mean acceptance rate of illicit DODs is 60\% for the Japanese subjects and $40.9 \%$ for the Korean subjects. A one-way ANOVA shows no significant difference between the Japanese and Korean groups either on the correctly accepted DODs, $F(1,40)=2.428, p=.158$, or on the incorrectly accepted DODs, $F(1,40)=1.634, p=.237$.

A look at individual responses shows that subjects from each of the three language groups accept illicit DODs at relatively high rates. The following all accept at least $40 \%$ of illicit forms: three of five from the L1 English group (CB at $50 \%$, DD at $80 \%$, and $\mathrm{HC}$ at $60 \%$ ); three of five from the L1 Japanese group (TN at $60 \%, \mathrm{CO}$ at $100 \%$, and CS at 100\%); and three of five from the L1 Korean group (CM at $40 \%$, WS at $60 \%$, and HEC at $60 \%$ ). It is noteworthy that the nonnative speakers who exhibit this overgeneralization are the relatively more proficient subjects. These instances of overgeneralization can be contrasted with the responses of one of the Korean subjects, $\mathrm{BC}$, who is extremely restrictive, never allowing the DOD form, whether licit or illicit.

With regard to responses to individual verbs, three verbs were misjudged 
Table 6. Response by individuals to double-object dative (DOD) with to-dative verbs

\begin{tabular}{|c|c|c|c|}
\hline Subjects & $\begin{array}{c}\text { Correctly } \\
\text { accepted DOD } \\
\text { with to-dative verbs } \\
(\text { e.g., showed } Y X)^{\mathrm{a}}\end{array}$ & $\begin{array}{c}\text { Incorrectly } \\
\text { accepted DOD } \\
\text { with to-dative verbs } \\
\left(\text { e.g., }{ }^{*} \text { said } Y X\right)^{\mathrm{b}}\end{array}$ & $\begin{array}{c}\text { Total DODs } \\
\text { accepted with } \\
\text { to-dative verbs }\end{array}$ \\
\hline \multicolumn{4}{|l|}{ English } \\
\hline$\stackrel{\mathrm{CB}}{ }$ & $(50 \%)$ & $(50 \%)$ & $4 / 8 \quad(50 \%)$ \\
\hline VA & $3 / 5 \quad(60 \%)$ & $1 / 5 \quad(20 \%)$ & $4 / 10 \quad(40 \%)$ \\
\hline DD & $5 / 5 \quad(100 \%)$ & $4 / 5 \quad(80 \%)$ & $9 / 10 \quad(90 \%)$ \\
\hline $\mathrm{HC}$ & $5 / 5 \quad(100 \%)$ & $3 / 5 \quad(60 \%)$ & $8 / 10 \quad(80 \%)$ \\
\hline $\mathrm{MH}$ & $3 / 5 \quad(60 \%)$ & $(0 \%)$ & $3 / 10 \quad(30 \%)$ \\
\hline NB & $5 / 5 \quad(100 \%)$ & $(20 \%)$ & $6 / 10 \quad(60 \%)$ \\
\hline Total & $23 / 29(79.3 \%)$ & $11 / 29(37.9 \%)$ & $34 / 58(58.6 \%)$ \\
\hline \multicolumn{4}{|l|}{ Japanese } \\
\hline $\mathrm{RN}$ & $(80 \%)$ & $(20 \%)$ & $5 / 10 \quad(50 \%)$ \\
\hline TN & $2 / 5 \quad(40 \%)$ & $(60 \%)$ & $5 / 10 \quad(50 \%)$ \\
\hline $\mathrm{CO}$ & $2 / 3 \quad(66.7 \%)$ & $3 / 3 \quad(100 \%)$ & $5 / 6 \quad(83.3 \%)$ \\
\hline MS & $3 / 4 \quad(75 \%)$ & $1 / 3 \quad(33.3 \%)$ & $4 / 7 \quad(57.1 \%)$ \\
\hline $\mathrm{CS}$ & $3 / 3 \quad(100 \%)$ & $4 / 4 \quad(100 \%)$ & $7 / 7 \quad(100 \%)$ \\
\hline Total & $14 / 20 \quad(70 \%)$ & $12 / 20 \quad(60 \%)$ & $26 / 40 \quad(65 \%)$ \\
\hline \multicolumn{4}{|l|}{ Korean } \\
\hline $\mathrm{BC}$ & $(0 \%)$ & $(0 \%)$ & $(0 \%)$ \\
\hline HW & $(75 \%)$ & $(25 \%)$ & $4 / 8 \quad(50 \%)$ \\
\hline $\mathrm{CM}$ & $(40 \%)$ & $(40 \%)$ & $4 / 10 \quad(40 \%)$ \\
\hline WS & $(60 \%)$ & $(60 \%)$ & $6 / 10 \quad(60 \%)$ \\
\hline HEC & $(60 \%)$ & $(60 \%)$ & $6 / 10 \quad(60 \%)$ \\
\hline Total & $11 / 22 \quad(50 \%)$ & $9 / 22(40.9 \%)$ & $20 / 44(45.5 \%)$ \\
\hline
\end{tabular}

a.g., The pig showed the sheep the fire engine.

be.g., *The pig said the giraffe the answer.

at very high rates. The verb to shout was accepted in the DOD $\left({ }^{*}\right.$ The giraffe shouted the pig the color) by nine of 13 subjects, including five of the six native speakers. The DOD-whisper sentence $\left({ }^{\star}\right.$ The tiger whispered the pig the secret) was similarly accepted by 10 of 16 subjects, evenly distributed among the three groups. The third verb, to throw, is considered licit in the DOD form (The sheep threw the giraffe the spoon); however, 10 of 14 subjects rejected it, three L1 English, two of four Japanese, and all five Koreans. ${ }^{22}$ It must be noted that the scenario accompanying this sentence mistakenly depicted the giraffe as failing to catch the spoon, which may have been perceived as violating the possession constraint, causing the DOD to be infelicitous.

To summarize the results of the to-dative double-object form: One Korean subject of low proficiency rejects it completely; other more proficient L2 children overgeneralize it. Indeed, there is evidence of overgeneralization from all three language groups. The native speaker results, then, echo those of the L1 acquisition literature. ${ }^{23}$ 
Table 7. Response by individuals to double-object dative (DOD) with for-dative verbs

\begin{tabular}{|c|c|c|c|}
\hline Subjects & $\begin{array}{c}\text { Correctly } \\
\text { accepted DOD } \\
\text { with for-dative verbs } \\
(\text { e.g., made } Y X)^{\mathrm{a}}\end{array}$ & $\begin{array}{c}\text { Incorrectly } \\
\text { accepted DOD } \\
\text { with for-dative verbs } \\
\left(\text { e.g., }{ }^{*} \text { held } Y X\right)^{\mathrm{b}}\end{array}$ & $\begin{array}{c}\text { Total DODs } \\
\text { accepted with } \\
\text { for-dative verbs }\end{array}$ \\
\hline \multicolumn{4}{|l|}{ English } \\
\hline$\stackrel{\mathrm{CB}}{ }$ & $4 / 4 \quad(100 \%)$ & $(0 \%)$ & $4 / 7 \quad(57.1 \%)$ \\
\hline VA & $4 / 5 \quad(80 \%)$ & $(0 \%)$ & $4 / 10 \quad(40 \%)$ \\
\hline DD & $5 / 5 \quad(100 \%)$ & $(0 \%)$ & $5 / 10 \quad(50 \%)$ \\
\hline $\mathrm{HC}$ & $5 / 5 \quad(100 \%)$ & $1 / 5 \quad(20 \%)$ & $6 / 10 \quad(60 \%)$ \\
\hline $\mathrm{MH}$ & $5 / 5 \quad(100 \%)$ & $(0 \%)$ & $5 / 10 \quad(50 \%)$ \\
\hline NB & $5 / 5 \quad(100 \%)$ & $(0 \%)$ & $5 / 10 \quad(50 \%)$ \\
\hline Total & $28 / 29(96.6 \%)$ & $1 / 28 \quad(3.6 \%)$ & $29 / 57(50.9 \%)$ \\
\hline \multicolumn{4}{|l|}{ Japanese } \\
\hline $\mathrm{RN}$ & $3 / 4 \quad(75 \%)$ & $5 / 5 \quad(100 \%)$ & $8 / 9 \quad(88.9 \%)$ \\
\hline TN & $(0 \%)$ & $3 / 5 \quad(60 \%)$ & $3 / 9 \quad(33.3 \%)$ \\
\hline $\mathrm{CO}$ & $2 / 3 \quad(66.7 \%)$ & $4 / 4 \quad(100 \%)$ & $6 / 7 \quad(85.7 \%)$ \\
\hline MS & $2 / 3 \quad(66.7 \%)$ & $1 / 3 \quad(33.3 \%)$ & $3 / 6 \quad(50 \%)$ \\
\hline $\mathrm{CS}$ & $4 / 4 \quad(100 \%)$ & $1 / 3 \quad(33.3 \%)$ & $5 / 7 \quad(71.4 \%)$ \\
\hline Total & $11 / 18(61.1 \%)$ & $14 / 20 \quad(70 \%)$ & $25 / 38(65.8 \%)$ \\
\hline \multicolumn{4}{|l|}{ Korean } \\
\hline $\mathrm{BC}$ & $2 / 3 \quad(66.7 \%)$ & $1 / 3 \quad(33.3 \%)$ & $3 / 6 \quad(50 \%)$ \\
\hline HW & $4 / 4 \quad(100 \%)$ & $1 / 3 \quad(33.3 \%)$ & $5 / 7 \quad(71.4 \%)$ \\
\hline $\mathrm{CM}$ & $4 / 5 \quad(80 \%)$ & $(0 \%)$ & $4 / 10 \quad(40 \%)$ \\
\hline WS & $4 / 5 \quad(80 \%)$ & $(20 \%)$ & $5 / 10 \quad(50 \%)$ \\
\hline HEC & $5 / 5 \quad(100 \%)$ & $(0 \%)$ & $5 / 10 \quad(50 \%)$ \\
\hline Total & $19 / 22(86.4 \%)$ & $3 / 21(14.3 \%)$ & $22 / 43(51.2 \%)$ \\
\hline
\end{tabular}

a.g., The giraffe made the pig a cup of tea.

be.g., *The tiger held the sheep the money.

For-Dative Sentences. Table 7 provides responses by individual to the DOD form of the benefactive for-dative sentences (e.g., The pig drew the sheep a picture; * The tiger finished the sheep the book). The L1 English children have adultlike grammars with regard to the for-dative double-object form. They accept licit DODs and reject the illicit ones. As for the nonnative children, there is evidence of overgeneralization in the Japanese results. As a group, they accept $70 \%$ of illicit DOD forms. Two Japanese subjects (RN and CO) accept all of the illicit DOD forms. TN also overextends to allow three of five illicit DOD forms (though he does reject licit DODs). In sum, three of the five Japanese subjects accept no less than $60 \%$ of forms not part of target language input.

The Japanese results are in stunning contrast with the Korean results: Table 7 reveals remarkably targetlike responses from the Korean children. They correctly accept licit DODs and correctly reject illicit DODs. In fact, as a group, only $14.3 \%$ of the illicit forms are accepted (compared to $70 \%$ for the Japanese group). The difference between the Japanese and Korean subjects' acceptance of illicit DODs is statistically significant by a one-way ANOVA test, $F(1,39)=$ 
$8.225, p<.05$. This is, notably, the sole difference to reach statistical significance across the data. For correct acceptance of licit for-dative DODs, the difference is also not statistically significant, $F(1,38)=1.767, p=.22$. In short, the overgeneralization seen in the Japanese results is not found in the Korean results.

As for responses to individual verbs, most nontargetlike responses were evenly split among the tokens. The single exception was acceptance of the verb to watch ( ${ }^{*}$ The pig watched the giraffe the marble) by four of the five Japanese subjects.

To summarize the double-object results for for-dative verbs: There is evidence of overgeneralization in the behavior of some Japanese children. The Korean subjects, by contrast, respond in a targetlike fashion to these fordative double-object forms, just like their native speaker counterparts. ${ }^{24}$

\section{DISCUSSION}

In regard to the L2 acquisition of the English double-object construction, two broad expectations stem from the FT-FA model: initial state effects and overgeneralization. From Full Transfer comes the expectation that Interlanguage development will differ based on differences between the L1 grammars. This is supported as the only significant difference between the two L2 groups occurred exactly where their L1s differ: DODs with benefactive for-datives; the Japanese subjects evince DOD overgeneralization, whereas the Korean children were targetlike. Recall that Japanese does not allow such double accusatives, but Korean does as long as the benefactive morpheme $c w u$-is present.

The L1 Koreans' near-targetlike responses on the double-object for-datives could be taken at face value, leading to the conclusion that they are just more advanced and have perhaps already passed through some unknown developmental sequence, ending up with a near-English grammar of double-object fordatives. Yet there are two arguments against this. First, there is no significant difference in proficiency scores between the Japanese and the Koreans. Second, the results on double-object to-dative sentences also indicate that the two L2 groups are in fact comparable. For these reasons we reject the idea that the Korean children are just generally more advanced in English than the Japanese children. Instead, we take the difference between the two groups' response patterns on double-object for-datives to reflect a divergence in their developmental paths, a divergence caused ultimately by the difference in their L2 initial states.

As for the second expectation, evidence of Full Access is also found in the data: At least $40 \%$ of illicit DODs are allowed by six of the 10 nonnative subjects with to-dative verbs and by three of the five Japanese subjects with fordative verbs. In sum, we find L1 English-like overgeneralization by Japanese and Korean subjects with to-datives and by Japanese with for-datives.

Let us now turn to our more specific hypotheses. Hypothesis 1 predicted that with regard to to-dative verbs for both L2 groups, Full Transfer would 
lead to initial restrictive behavior and Full Access would later lead to overgeneralization, as in L1 acquisition. Although overgeneralization is clearly borne out by results from three subjects in each of the L1 groups, the expected restrictiveness is only found for one subject, the Korean BC. It is noteworthy that this subject is the Korean with the lowest proficiency (see Table 4). As Full Transfer is an initial-state phenomenon, this is an entirely expected result. The other subjects, who have also had at least a year's exposure to English, have evidently moved beyond this point, restructuring their Interlanguage based on what is present in the input. In other words, from the perspective of FT-FA, the grammars of Japanese and Korean have nothing to draw from, overt morphology or otherwise, in the L2 acquisition of the English DOD construction with to-dative verbs. Japanese and Korean children acquiring English should thus initially be restrictive but then come to look like L1 acquirers of English in this domain, and this seems to be generally true in our results: There is some evidence of undergeneration and some evidence of overgeneration. Hypothesis 1 , then, is largely supported.

Hypothesis 2 is concerned with for-dative verbs, predicting the same result as hypothesis 1, but only for the Japanese group. This is because Japanese does not have an analogous dative alternation to English with for-datives, but Korean does. As with the first hypothesis, we find evidence of overgeneralization from these Japanese children, but we do not find evidence for restrictive behavior. This is unsurprising given that none of the Japanese children were restrictive in response to the to-dative verbs either. Thus, much like for hypothesis 1, we maintain that these Japanese subjects are at a point in their English development where initial-state effects have been overridden by UGconstrained acquisition, resulting in L1-like acquisition.

Hypotheses 3 and 4 address the issue of level of transfer. This is relevant for the Korean speakers' acquisition of for-dative verbs because there is a double-object variant in Korean, and further, this variant requires a piece of overt morphology, $c w u$ - According to hypothesis 3 , this morphology would play no role, and instead transfer would occur at the level of syntax. From this stems the prediction that because Korean productively allows benefactive DODs, Korean children would readily accept licit and illicit double-object forms with fordatives right from the beginning. Hypothesis 4, by contrast, predicted that there is transfer at the level of morphology, which means that Korean children would initially be restrictive because English lacks analogous overt morphology to license the benefactive DOD construction. As shown in Table 7, the Koreans do not overgeneralize here, clearly falsifying hypothesis 3 . We argue that the targetlike DOD for-dative results support hypothesis 4 .

We suggest that when Koreans begin to acquire English, they initially "look for" a piece of morphology analogous to $c w u$ - to license the DOD in English (for a related proposal, see Lardiere, 2000). As no such benefactive verbal element exists in English, their Interlanguage grammar will be unable to license a benefactive DOD, the result of which is that they will initially disallow all double-object for-dative forms. Yet, benefactive DODs will continue to be present 
Table 8. Transfer asymmetry: Morphologically overt versus nonovert syntactic argument alternations

\begin{tabular}{lccc}
\hline & & $\begin{array}{c}\text { Target } \\
\text { language }\end{array}$ & $\begin{array}{c}\text { Predicted } \\
\text { relative } \\
\text { difficulty }\end{array}$ \\
\hline $\begin{array}{l}\text { Nonovert-overt } \\
\text { Overt-nonovert }\end{array}$ & - & + & Less \\
\hline
\end{tabular}

in the input. So, despite the absence of an overt benefactive morpheme in English, Koreans will start to learn the DOD form of for-dative verbs on the basis of positive evidence, and they will continue to do so on a verb-by-verb basis. Thus, the remarkably targetlike results of the L1 Korean children on the double-object for-dative sentences is, in fact, evidence for hypothesis 4, which states that Korean speakers will initially be restrictive in their acceptance of double-object for-datives. The continued rejection of illicit DODs with fordatives stems from the L1 grammar, not because the L1 grammar disallows a double-object structure, but rather because the piece of morphology needed to license it is not forthcoming in the input. The reason for this continued rejection of illicit benefactive DODs in English remains essentially unchanged from their L2 initial state: They can't license it, so they don't; they don't hear them, so there's nothing to learn. In contrast, examples in the input of licit benefactive DODs results in the learning of these forms one by one, exhibiting the conservative behavior originally hypothesized for L1 acquisition by Baker (1979).

\section{CONCLUSION}

Recall that, according to Montrul (1997), the types of effects that transfer of argument-affecting morphology will have depend on its overt versus nonovert status in both the source and target languages. Although Korean relies on overt morphology to mark such an alternation, English does not. As such, the task facing our Korean speakers is similar to the task facing the Spanish acquirers of the English inchoative in the study from Montrul summarized earlier. In both, the L1 uses overt morphology to mark an argument structure alternation, but the target language does not. Montrul identified this L1-target language opposition to be the one most likely to cause difficulty and be prone to error. That is, Montrul tentatively suggested that there is an asymmetry in terms of ease or difficulty when the source and target languages differ on whether the argument structure alternations are morphologically marked overtly or not (p. 272). ${ }^{25}$ This asymmetry is schematized in Table 8. According to Montrul, speakers of a language that does not morphologically mark a syntactic-argument alternation overtly who are acquiring a language that does (L1 
nonovert-target language overt) are advantaged in comparison to speakers of a language that does morphologically mark such an alternation overtly who are acquiring a language that does not (L1 overt-target language nonovert). This is because the target language will provide overt morphological evidence in the case of a nonovert- overt mismatch, disconfirming the assumption of the L1 that the syntactic-argument alternation is not overtly signaled. In the case of an overt-nonovert mismatch, there will be no overt morphological cues to override the assumption of the L1 that overt morphological markings are needed.

The Spanish acquirers of English in Montrul's (1997) study exemplify the overt-nonovert mismatch, and, as expected, they had difficulty with the licit inchoatives (especially in comparison to the Turkish speakers). The Koreans in our study also exemplify an overt-nonovert mismatch in the case of double-object for-datives-but the effect in terms of behavior relative to the target is the converse. On our analysis, the Koreans are ostensibly conferred an advantage over their Japanese peers, precisely because the L1 overtly marks the double-accusative benefactive dative. This is not to say that the analysis of English benefactive DODs (i.e., the defining conditions on grammaticality) that the Korean children have is the same as native speakers'. Indeed, we have argued just the opposite. To the extent that the Koreans are accepting English double-object benefactive datives, it is because, we suggested, they have noted one-by-one which verbs do occur in double-object contexts. That they reject illicit benefactive DODs is the result not of an English-like grammar but rather of their L1 grammar in combination with no input to override the requirement of a morphological licensor. Nonetheless, the effect is more targetlike behavior, unlike the effect in the case of Montrul's Spanish subjects (where the target is a grammatical inchoative form).

In sum, if our analysis of the Korean children's results is on the right track (and one can test it by using nonce verbs), then its juxtaposition with Montrul's (1997) findings highlights just how complex the issue of transfer in L2 acquisition is. We have argued that there is transfer at the level of morphology that sees its effects at the level of syntax. From this perspective, it is the transfer of the argument-changing properties of the Korean benefactive cwumorpheme that (a) explains the Korean children's behavior on English doubleobject benefactive for-datives, and (b) explains why the English Interlanguage profiles of the Japanese and Korean children diverged here but not elsewhere. In conclusion, the definite L1 effect in these child Interlanguage data, on the one hand, and the evidence of overgeneralization, on the other, show that child L2 acquirers do share properties with both L2 adult acquirers and L1 child acquirers. We hope to have "demonstrated you minimally these two results."

(Received 30 November 2001)

\section{NOTES}

1. On the ungrammaticality of (2b) and (4b), which satisfy the possession constraint, see the upcoming discussion. Note also that possession may be physical or metaphorical. In the spirit of 
Pinker (1989), the DOD in (1), for instance, rests on the idea that Lauren has come to possess an image of the picture as a result of Nikki's showing the picture to her.

2. The possession constraint also exists with for-dative alternations, but the for-dative doubleobject form has a different thematic core, namely, "X acts on Z for Z to have Y" (Pinker, 1989, p. 221). The difference is that the Agent intends the Beneficiary to possess the Theme, whether or not there is a change of possession. The point is that potential possession exists.

3. This Latinate constraint is often deemed morphophonological in nature because of stress patterns. Native stems are typically either monosyllabic or bisyllabic with initial stress. Latinate stems that do participate in the dative alternation follow this stress pattern of native stems. For example, promise alternates but repeat does not. See Pinker (1989, pp. 118-123) for an extensive discussion of the Latinate versus native distinction. We refer to this as the "Latinate constraint."

4. The following abbreviations are used: $\mathrm{ACC}=$ accusative; $\mathrm{BEN}=$ benefactive; $\mathrm{CAUS}=$ causative; $\mathrm{DAT}=$ dative $; \mathrm{DECL}=$ declarative $; \mathrm{GEN}=$ genitive $; \mathrm{L}=$ linker $; \mathrm{NEG}=$ negative $; \mathrm{NOM}=$ nominative; $\mathrm{PASS}=$ passive; REFL = reflexive.

5. Note that word order is not fixed in Japanese in that, for example, the accusative object can precede the dative, as in (i). This is not an instance of argument structure alternation, but rather a product of scrambling.

(i) Hanako-ga hagaki-o Taro-ni oku-tta.

Hanako-NOM postcard-ACC Taro-to/DAT send-PAST

"Hanako sent a postcard to Taro."

6. Arguments that raise doubt about $-n i$ (always) being a case marker include the following: (a) According to Kuroda (1965), in Japanese the delimiters -sae "even" and -mo "too" cannot co-occur with case markers -ga and -o, but they can co-occur with postpositions. It is well established that -sae and -mo can co-occur with -ni. This argues for analyzing -ni as a postposition; (b) Numeral quantifiers can "float" out of case-marked NPs but not out of NPs within a PP. According to Sadakane and Koizumi (1995), Goal -ni-marked indirect objects can occur with floating numeral quantifiers, whereas benefactive -ni postpositions cannot; (c) Both -o and -ni objects can passivize, which prompted Baker (1988) to consider Japanese a double structural-case language (see also Miyagawa, 1997). However, that a -ni-marked NP can passivize is not evidence for direct-object status because NPs other than direct objects can also passivize in Japanese. See Kubo (1992) for arguments that possessor NPs can passivize, even in nonadversative sentences (and hence they are arguably not instances of the "adversity passive").

7. The light verb hata "to do" seems, superficially, to allow double accusatives. However, this construction is generally considered biclausal and therefore not the same as the arguably monoclausal double-accusative construction that occurs with the $c w u$ - verbal element (see note 9). See Lee (1989) and references therein for discussion. There is, however, a small number of other verbs that allows double accusatives: cwuta "to give," kaluchita "to teach," and mekita "to feed." These verbs can be seen as exceptional, and so their English analogues were avoided in this study. Although J. Yoon (personal communication, 6 June 2000) tells us that ponayta "to send" allows the double-accusative construction, our native speaker consultants generally do not agree, and Hong (1991, p. 167) and O'Grady (1991, p. 264, [14]) explicitly stated that it is disallowed.

8. There is a degree of native speaker variation here (as elsewhere; see fn. 7); some native speakers find some of these sentences awkward.

9. An anonymous SSLA reviewer points out that the Korean benefactive verbal construction may be analyzed as biclausal and therefore not analogous to the double-object construction in English. A monoclausal analysis has been argued for by Lee (1993) and is adopted here (see also Jo, 1990; Kang, 1992; and Lee, 1991, all three cited in You, 1996). Arguments for a monoclausal analysis include the following: (a) There is only a single set of inflectional features (e.g., tense) on the complex predicate. The inability of both verbal elements to carry Infl features has been a standard test for monoclausal status crosslinguistically (see Bamgbose, 1973; Byrne, 1990; Foley \& Olsen, 1985; Schachter, 1974; Sebba, 1987; Stahlke, 1970); (b) No (phrasal) material can intervene between the two verbal elements, apart from particles such as the topic marker - $(n)$ un and the delimiter -man "only" (J. Whitman, personal communication, 15 March 2000; You); (c) Negation always takes scope over the entire complex predicate, never over just one of the two verbal elements (Lee, 1993); (d) Although the morpheme - $e$ suffixed to the first verb has been taken to be an infinitive marker (Choe, 1988; Sohn, 1999) or a complementizer (Lee, 1976; Yang, 1976; You), we follow Lee (1993, p. 450) in claiming "that $-e$ is just a dummy-morpheme linker which is used to satisfy the requirement of morphological closure," as no bare verb stems are allowed in Korean. Though we adopt a monoclausal analysis of 
the Korean benefactive verbal construction with $c w u$-, more crucial is the existence of two formsthat is, an alternation in Korean-as shown in the upcoming text.

10. Juffs (1996) observed that narrow classes of verbs are defined by highly idiosyncratic features that may be "less likely to be involved in constraining argument structure alternations crosslinguistically" (p. 53).

11. See Sawyer (1996) for a study that does claim to find evidence for native Japanese speakers' knowledge of the English narrow constraints.

12. Inagaki (1997) provides the example in (i) (his [10], p. 643).

(i) *John-ga Mary-ni hako-o osi/hakon/hii/age-ta

John-NOM Mary-DAT box-ACC push/carry/pull/lift-PAST

"John pushed/carried/pulled/lifted a box to Mary."

13. In addition to these subjects, three Japanese and two Korean children were tested but excluded from the study because they were unable to complete the training portion of the experiment adequately. It is perhaps noteworthy that four of these five subjects were under the age of 6 years.

14. There is also a local Korean Saturday school. All five of the Korean test subjects attend that school and are therefore similar to the Japanese subjects in this respect.

15. An anonymous SSLA reviewer asks whether the Korean children were tested for L1 knowledge of double accusatives with the benefactive verbal construction. Although we did not do this (and acknowledge that it would have been better if we had), given that all the Korean children in this study were at least 6;6 years old and more proficient in their L1 than English, we did not think it was problematic to assume their control over double accusatives with the Korean analogues of the benefactive verbs tested in our study, first, because they are all very common verbs and, second, because the double accusative is itself common in colloquial Korean, according to our consultants. In short, we assume that the mechanisms that license double-accusative structure in Korean are at play in the grammar of native Korean speakers by the age of $6 ; 6$.

16. An anonymous SSLA reviewer questions the use of a grammaticality judgment task, citing Slavoff and Johnson (1995), who eliminated children younger than 7;6 because they performed at chance level. Yet, the inability of their subjects to give judgments may have been due to their specific procedure. For instance, their children judged sentences in a lab setting, listening to them through headsets. There was no context, visual or otherwise, to situate the sentences or hold their interest; nor is it clear that the children were trained to do the task. Additionally, as McDaniel and Cairns (1996) noted, Schlisselberg (1988) demonstrated that children as young as 3;6 are able to give reliable judgments, as did de Villiers and de Villiers (1974) with 4-year-olds. See also note 24.

17. All of the practice and pretest sentences were based on points of grammar that the subjects were expected to have already acquired, including basic word order and subject-verb agreement using the copula be, which is typically acquired early.

18. Note that all objects in the test sentences were full DPs and not pronominals. This was due to the observation made by Mazurkewich and White (1984) that an illicit DOD in English is deemed more acceptable if the indirect object is pronominalized, as in (i) and (ii).

(i) a. *Anne recommended Tom a restaurant.

b. ?Anne recommended him a restaurant.

(ii) a. *Anne selected Tom a tie.

b. ?Anne selected him a tie.

(from note 8, Mazurkewich \& White, p. 267)

19. Two of these six sentence types, for a total of 10 sentence pairs, were interspersed throughout the target sentences and served as distracters. Being irrelevant to this paper, they will not be discussed. See Whong-Barr (1999) for details.

20. In comparing L1 child data across languages, Slobin (1993) defined "utterance" as a clause with a "unified" predicate (unified in that it expresses a single activity, event, or state). Additionally, given the nature of spoken English, an utterance may include a clause without a predicate if that predicate was deleted by gapping or ellipsis, or if the copula had simply been dropped. This definition of utterance accommodates instances in which some children at times simply listed the objects they saw in the pictures, without using complex syntax. Examples of such cases, taken from the transcript of $\mathrm{BC}$ (age 7;10), include (i) and (ii), which contrast with (iii).

(i) seaside

(ii) ball

(iii) there's balls 
21. Larsen-Freeman (1983) analyzed her L2 data by T-units, not utterances. The decision to use utterances over T-units in this study was due to the often fragmentary nature of the data.

22. One L1 Japanese child, CS, could not decide on the acceptability of this sentence. This is the sole instance in which a child was unable to make a judgment on the target sentences.

23. The three native subjects' overgeneralizations were not confined to Latinate verbs: whisper to, shout to, say to, and, anticipating the results from the next section on double-object for-datives, keep for.

24. Note that, whereas the overall response pattern to the double-object to-datives was not especially well behaved, the combination of consistent response patterns on (a) the PD sentences by all three groups and (b) the double-object for-datives by the native speakers and by the Koreans validates the test. The children did understand what they were being asked to do and were able to do it. From this we are also led to infer that the "messier" results are genuine reflections of their grammars. (We also therefore do not accept the suggestion by an anonymous SSLA reviewer that these subjects are too young to make grammaticality judgments.)

25. In the context of her summary discussion of verbs with alternating argument structures "and especially with the inchoative forms," Montrul (1997) wrote that it "would appear that learning a morphologically complex language is easier than learning languages with poor morphological clues" (p. 273).

\section{REFERENCES}

Aoun, J., \& Li, Y. (1989). Scope and constituency. Linguistic Inquiry, 20, 141-172.

Baker, C. L. (1979). Syntactic theory and the projection problem. Linguistic Inquiry, 10, 533-581.

Baker, M. (1988). Incorporation: A theory of grammatical function changing. Chicago: University of Chicago Press.

Bamgbose, A. (1973). On serial verbs and verbal status. Journal of West African Languages, 9, 17-48.

Bley-Vroman, R. (1990). The logical problem of foreign language acquisition. Linguistic Analysis, 20, $3-49$.

Bley-Vroman, R., \& Yoshinaga, N. (1992). Broad and narrow constraints on the English dative alternation: Some fundamental differences between native speakers and foreign language learners. University of Hawai ' $i$ Working Papers in ESL, 11, 157-199.

Bowerman, M. (1988). The "no-negative evidence" problem: How do children avoid constructing an overly general grammar? In J. Hawkins (Ed.), Explaining language universals (pp. 73-101). Oxford: Blackwell.

Byrne, F. (1990). Tense marking and the serial structures. In B. D. Joseph \& A. M. Zwicky (Eds.), Working papers in linguistics 39 (pp. 149-177). Columbus: Ohio State University.

Choe, H. (1986). Syntactic adjunction, A-chain, and the ECP: Multiple identical case construction in Korean. In J. McDonough \& B. Plunkett (Eds.), Proceedings of NELS 17 (pp. 100-120). Amherst, MA: GSIL Publications.

Choe, H. (1988). Restructuring parameters and complex predicates: A transformational approach. Unpublished doctoral dissertation, Massachusetts Institute of Technology, Cambridge.

de Villiers, J., \& de Villiers, P. (1974). Competence and performance in child language: Are children really competent to judge? Journal of Child Language, 1, 11-22.

Foley, W., \& Olsen, M. (1985). Clausehood and serialization. In J. Nichols \& A. Woodbury (Eds.), Grammar inside and outside the clause (pp. 17-60). New York: Cambridge University Press.

Goldsmith, J. (1980). Meaning and mechanism in grammar. In S. Kuno (Ed.), Harvard studies in syntax and semantics III (pp. 423-449). Cambridge, MA: Harvard University Linguistics Department.

Green, G. (1974). Semantics and syntactic regularity. Bloomington: Indiana University Press.

Grimshaw, J. (1989). Getting the dative alternation. In I. Laka \& A. Mahajan (Eds.), MIT working papers 10: Functional heads and clause structure (pp. 113-122). Cambridge, MA: Department of Linguistics and Philosophy, Massachusetts Institute of Technology.

Gropen, J., Pinker, S., Hollander, M., Goldberg, R., \& Wilson, R. (1989). The learnability and acquisition of the dative alternation in English. Language, 65, 203-257.

Harada, S. (1973). Counter equi NP deletion. Annual Bulletin 7 (pp. 113-147). Tokyo: Research Institute of Logopedics and Phoniatrics, University of Tokyo.

Hong, K. S. (1991). Argument selection and case marking in Korean. Unpublished doctoral dissertation, Stanford University, Stanford, CA.

Huang, S. (1994). A comparative study of the dative alternation in Mandarin and Taiwanese. Unpublished manuscript, University of Hawai'i at Manoa. 
Inagaki, S. (1997). Japanese and Chinese learners' acquisition of the narrow-range rules for the dative alternation in English. Language Learning, 47, 637-669.

Jackendoff, R. (1990). Semantic structures. Cambridge, MA: MIT Press.

Jo, I. H. (1990). Multi-verb constructions in Korean. In B. D. Joseph \& A. M. Zwicky (Eds.), Working papers in linguistics 39 (pp. 265-287). Columbus: Ohio State University.

Johnson, J., \& Newport, E. (1989). Critical period effects in second language learning: The influence of maturational state on the acquisition of English as a second language. Cognitive Psychology, $21,60-99$.

Johnson, K. B. (1991). Object positions. Natural Language \& Linguistic Theory, 9, 577-636.

Juffs, A. (1996). Learnability and the lexicon. Amsterdam: Benjamins.

Kang, S. Y. (1992). Serial verbs in Korean. In S. W. Cho \& H. H. Lee (Eds.), A festschrift for Tae-ok Kim (pp. 513-531). Seoul: Hankwuk Munhwasa.

Kubo, M. (1992). Japanese passives. Journal of Institute of Language and Culture Studies, 23, 231-302.

Kuroda, S.-Y. (1965). Generative grammatical studies in the Japanese language. Unpublished doctoral dissertation, Massachusetts Institute of Technology, Cambridge.

Lardiere, D. (2000). Mapping features to forms in second language acquisition. In J. Archibald (Ed.), Second language acquisition and linguistic theory (pp. 102-129). Oxford: Blackwell.

Larsen-Freeman, D. (1983). Assessing global second language proficiency. In H. Seliger \& M. Long (Eds.), Classroom oriented research in second language acquisition (pp. 287-304). Rowley, MA: Newbury House.

Larson, R. (1988). On the double object construction. Linguistic Inquiry, 19, 335-391.

Lee, H. B. (1976). Notes on pronouns, reflexives, and pronominalization. Ehak Yunkwu (Linguistic Research), 12, 253-263.

Lee, K. (1989). About the so-called double object construction in Korean. Hawai $i$ Working Papers in Linguistics, 21, 101-130.

Lee, K. (1991). Multiple accusative constructions in Korean and the Stratal Uniqueness Law. Unpublished doctoral dissertation, University of Hawai'i at Manoa.

Lee, S. H. (1993). The syntax of serialization in Korean. In P. Clancy (Ed.), Japanese/Korean Linguistics (Vol. 2, pp. 447-463). Stanford, CA: CSLI Publications.

Levin, B. (1993). English verb classes and alternations: A preliminary investigation. Chicago: University of Chicago Press.

MacWhinney, B., \& Snow, C. (1985). The child language data exchange system. Journal of Child Language, 12, 271-296.

Mazurkewich, I., \& White, L. (1984). The acquisition of the dative alternation: Unlearning overgeneralizations. Cognition, 16, 261-283.

McDaniel, D., \& Cairns, H. (1990). The child as informant: Eliciting intuitions from young children. Journal of Psycholinguistic Research, 19, 331-344.

McDaniel, D., \& Cairns, H. (1996). Eliciting judgments of grammaticality and reference. In D. McDaniel, C. McKee, \& H. Cairns (Eds.), Methods for assessing children's syntax (pp. 233-254). Cambridge, MA: MIT Press.

Miyagawa, S. (1997). Against optional scrambling. Linguistic Inquiry, 29, 1-25.

Montrul, S. (1997). Transitivity alternations in second language acquisition: A crosslinguistic study of English, Spanish, and Turkish. Unpublished doctoral dissertation, McGill University, Montreal.

O'Grady, W. (1991). Categories and case: The sentence structure of Korean. Amsterdam: Benjamins.

Pinker, S. (1989). Learnability and cognition: The acquisition of argument structure. Cambridge, MA: MIT Press.

Poser, W. (1981). "The double-o constraint": Evidence for a direct object relation in Japanese? Unpublished manuscript, Massachusetts Institute of Technology, Cambridge.

Sadakane, K., \& Koizumi, M. (1995). On the nature of the "dative" particle $n i$ in Japanese. Linguistics, $33,5-33$

Sawyer, M. (1996). L1 and L2 sensitivity to semantic constraints on argument structure. In A. Stringfellow, D. Cahana-Amitay, E. Hughes, \& A. Zukowski (Eds.), Proceedings of the 20th annual Boston University Conference on Language Development (Vol. 2, pp. 646-657). Somerville, MA: Cascadilla Press.

Schachter, P. (1974). A non-transformational account of serial verbs. Studies in African Linguistics, 5, 253-270.

Schlisselberg, G. (1988). Development of selected conservation skills and the ability to judge sentence well-formedness in young children. Unpublished doctoral dissertation, City University of New York 
Schwartz, B. D., \& Sprouse, R. A. (1994). Word order and nominative case in nonnative language acquisition: A longitudinal study of (L1 Turkish) German Interlanguage. In T. Hoekstra \& B. D. Schwartz (Eds.), Language acquisition studies in generative grammar: Papers in honor of Kenneth Wexler from the 1991 GLOW Workshops (pp. 317-368). Amsterdam: Benjamins.

Schwartz, B. D., \& Sprouse, R. A. (1996). L2 cognitive states and the Full Transfer/Full Access model. Second Language Research, 12, 40-72.

Sebba, M. (1987). The syntax of serial verbs. Amsterdam: Benjamins.

Slavoff, G., \& Johnson, J. (1995). The effects of age on the rate of learning a second language. Studies in Second Language Acquisition, 17, 1-16.

Slobin, D. (1993). Coding child language data for crosslinguistic analysis. In J. Edwards \& M. Lampert (Eds.), Talking data: Transcription and coding in discourse research (pp. 207-219). Mahwah, NJ: Erlbaum.

Sohn, H. M. (1999). The Korean language. New York: Cambridge University Press.

Song, N. S. (1993). Thematic relations and transitivity in English, Japanese, and Korean. Honolulu: Center for Korean Studies, University of Hawai'i.

Stahlke, H. (1970). Serial verbs. Studies in African Linguistics, 1, 60-99.

White, L. (1987). Markedness and second language acquisition. Studies in Second Language Acquisition, 9, 261-286

White, L. (1991). Argument structure in second language acquisition. French Language Studies, 1, 189207.

Whong-Barr, M. (1999). A child L2 study: Acquisition of the English dative alternation by Korean and Japanese speakers. Unpublished Master's dissertation, University of Durham, United Kingdom.

Yang, D. W. (1976). Korean negation revisited. Linguistic Journal of Korean, 11, 243-248.

You, S. H. (1996). Argument licensing in complex verbal constructions in Korean. Unpublished doctoral dissertation, University of Hawai'i at Manoa. 


\section{APPENDIX A}

\section{TEST SENTENCES}

\section{Alternating To-Dative Sentences}

1. a. The sheep threw the spoon to the giraffe. b. The sheep threw the giraffe the spoon.

2. a. The pig showed the fire engine to the sheep. b. The pig showed the sheep the fire engine.

3. a. The giraffe brought the cup to the tiger.

b. The giraffe brought the tiger the cup.

4. a. The sheep sent the book to the pig. b. The sheep sent the pig the book.

5. a. The tiger handed the fork to the giraffe. b. The tiger handed the giraffe the fork.

\section{Nonalternating To-Dative Sentences}

1. a. The pig said the answer to the giraffe.

b. *The pig said the giraffe the answer.

2. a. The tiger whispered the secret to the pig.

b. *The tiger whispered the pig the secret.

3 . a. The pig repeated the word to the tiger.

b. *The pig repeated the tiger the word.

4. a. The tiger explained the answer to the pig.

b. *The tiger explained the pig the answer.

5. a. The giraffe shouted the color to the pig.

b. *The giraffe shouted the pig the color.

\section{Alternating For-Dative Sentences}

1. a. The giraffe made a cup of tea for the pig. b. The giraffe made the pig a cup of tea.

2. a. The pig bought a marble for the giraffe. b. The pig bought the giraffe a marble.

3. a. The pig drew a picture for the sheep. b. The pig drew the sheep a picture.

4. a. The tiger found a spoon for the sheep. b. The tiger found the sheep a spoon.

5. a. The sheep got a book for the tiger. b. The sheep got the tiger a book.

\section{Nonalternating For-Dative Sentences}

1. a. The tiger held the money for the sheep. b. *The tiger held the sheep the money.

2. a. The giraffe kept the car for the pig. b. *The giraffe kept the pig the car.

3. a. The pig watched the marble for the giraffe. b. *The pig watched the giraffe the marble. 
4. a. The giraffe fixed the fire engine for the sheep.

b. *The giraffe fixed the sheep the fire engine.

5. a. The tiger finished the book for the sheep.

b. *The tiger finished the sheep the book.

\section{APPENDIX B}

\section{NATIVE JUDGMENTS}

\section{Japanese Judgments}

1. *Hanako-ga Taro-o boru-o motte/watashi/oku/mise/nage-ta.

"Hanako brought/handed/sent/showed/threw the ball to Taro."

2. *Hanako-ga Taro-o kotae-o setsumeisi/kurikaesi/i/saken/sasayai-ta.

"Hanako explained/repeated/said/shouted/whispered the answer to Taro."

3. *Hanako-ga Taro-o hon-o katteage/mitsuketeage/totteage/kiipus/motteage-ta. "Hanako bought/found/got/kept/held the book for Taro."

4. *Hanako-ga Taro-o e/kaiki/sigoto/kuruma/saifu-o kai/tsu/siage/nos/mitei-ta.

"Hanako drew the picture/made the cake/finished the job/fixed the car/watched the wallet for Taro."

\section{Korean Judgments (Double-Accusative Objects Not Acceptable)}

1. a. Mia-ka Yong-eykey kong-ul tenci-essta.

b. *Mia-ka Yong-ul kong-ul tenci-essta.

"Mia threw the ball to Yong."

2. a. Mia-ka Yong-eykey samwusil-ul poy-essta.

b. *Mia-ka Yong-ul samwusil-ul poy-essta.

"Mia showed the office to Yong."

3. a. Mia-ka Yong-eykey chayk-ul kacyeka-ssta.

b. *Mia-ka Yong-ul chayk-ul kacyeka-ssta.

"Mia brought the book to Yong."

4. a. Mia-ka Yong-eykey chayk-ul ponay-ssta.

b. *Mia-ka Yong-ul chayk-ul ponay-ssta. $\dagger$

"Mia sent the book to Yong."

5. a. Mia-ka Yong-eykey ca-lul kenney-essta.

b. *Mia-ka Yong-ul ca-lul kenney-essta.

"Mia handed the ruler to Yong."

6. a. Mia-ka Yong-eykey taytap-ul hay-essta.

b. *Mia-ka Yong-ul taytap-ul hay-essta.

"Mia said the answer to Yong."

7. a. Mia-ka Yong-eykey pimil-ul soksaki-essta.

b. *Mia-ka Yong-ul pimil-ul soksaki-essta.

"Mia whispered the secret to Yong."

$\dagger$ †See Note 7. 
8. a. Mia-ka Yong-eykey taytap-ul panpok-hay-essta. b. *Mia-ka Yong-ul taytap-ul panpok-hay-essta.

"Mia repeated the answer to Yong."

9. a. Mia-ka Yong-eykey taytap-ul selmyeng-hay-essta.

b. *Mia-ka Yong-ul taytap-ul selmyeng-hay-essta.

"Mia explained the answer to Yong."

10. a. Mia-ka Yong-eykey taytap-ul solichye-ssta.

b. *Mia-ka Yong-ul taytap-ul solichye-ssta.

"Mia shouted the answer to Yong."

\section{Korean Judgments (Double-Accusative Objects Acceptable)}

1. a. Mia-ka Yong-eykey kheyik-ul mantule cwu-essta. b. Mia-ka Yong-ul kheyik-ul mantule cwu-essta. "Mia made the cake for Yong."

2. a. Mia-ka Yong-eykey chayk-ul sa cwu-essta.

b. Mia-ka Yong-ul chayk-ul sa cwu-essta.

"Mia bought the book for Yong."

3. a. Mia-ka Yong-eykey kulim-ul kulye cwu-essta.

b. Mia-ka Yong-ul kulim-ul kulye cwu-essta.

"Mia drew the picture for Yong."

4. a. Mia-ka Yong-eykey yelsoi-lul chaca cwu-essta.

b. Mia-ka Yong-ul yelsoi-lul chaca cwu-essta.

"Mia found the keys for Yong."

5. a. Mia-ka Yong-eykey chayk-ul kwuhay cwu-essta.

b. Mia-ka Yong-ul chayk-ul kwuhay cwu-essta.

"Mia got the book for Yong."

6. a. Mia-ka Yong-eykey kapang-ul tule cwu-essta.

b. Mia-ka Yong-ul kapang-ul tule cwu-essta.

"Mia held the bag for Yong."

7. a. Mia-ka Yong-eykey ton-ul pokwanhay cwu-essta.

b. Mia-ka Yong-ul ton-ul pokwanhay cwu-essta.

"Mia kept the money for Yong."

8. a. Mia-ka Yong-eykey cha-lul poye cwu-essta.

b. Mia-ka Yong-ul cha-lul poye cwu-essta.

"Mia watched the car for Yong."

9. a. Mia-ka Yong-eykey poksaki-lul kochye cwu-essta.

b. Mia-ka Yong-ul poksaki-lul kochye cwu-essta.

"Mia fixed the photocopier for Yong."

10. a. Mia-ka Yong-eykey chayk-ul ilke cwu-essta.

b. Mia-ka Yong-ul chayk-ul ilke cwu-essta.

"Mia finished reading the book for Yong." 


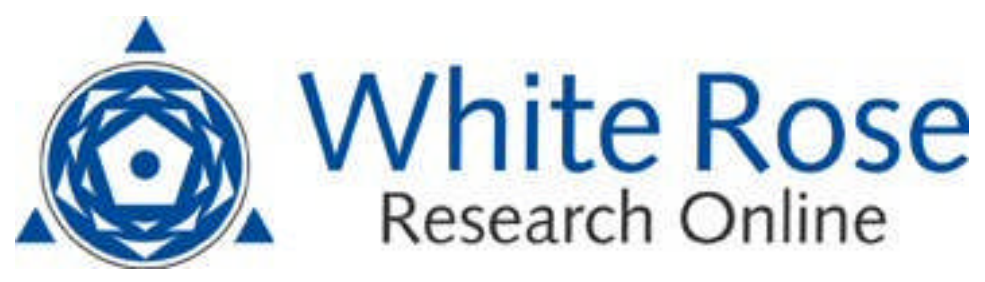

\section{Universities of Leeds, Sheffield and York http://eprints.whiterose.ac.uk/}

This is an author produced version of a paper published in Studies in Second Language Acquisition

White Rose Research Online URL for this paper:

http://eprints.whiterose.ac.uk/id/eprint/77360

\section{Paper:}

Whong-Barr, MK and Schwartz, BD (2002) Morphological and syntactic transfer in child L2 acquisition of the English dative alternation. Studies In Second Language Acquisition, 24 (4). $579-616$

http://dx.doi.org/10.1017/S0272263102004035 